\title{
Use of soil moisture dynamics and patterns at different spatio-temporal scales for the investigation of subsurface flow processes
}

\author{
T. Blume ${ }^{1,2, *}$, E. Zehe ${ }^{3}$, and A. Bronstert ${ }^{1}$ \\ ${ }^{1}$ Institute for Geoecology, Section of Hydrology and Climatology, University of Potsdam, Germany \\ ${ }^{2}$ Helmholtz Centre Potsdam, GFZ German Research Centre for Geosciences, Germany \\ ${ }^{3}$ Institute for Water and Environment, Technical University Munich, Germany \\ "Invited contribution by T. Blume, one of the EGU Young Scientists' Outstanding Poster Paper (YSOPP) Award winners 2008.
}

Received: 3 August 2007 - Published in Hydrol. Earth Syst. Sci. Discuss.: 9 August 2007

Revised: 2 June 2009 - Accepted: 29 June 2009 - Published: 17 July 2009

\begin{abstract}
Spatial patterns as well as temporal dynamics of soil moisture have a major influence on runoff generation. The investigation of these dynamics and patterns can thus yield valuable information on hydrological processes, especially in data scarce or previously ungauged catchments. The combination of spatially scarce but temporally high resolution soil moisture profiles with episodic and thus temporally scarce moisture profiles at additional locations provides information on spatial as well as temporal patterns of soil moisture at the hillslope transect scale. This approach is better suited to difficult terrain (dense forest, steep slopes) than geophysical techniques and at the same time less cost-intensive than a high resolution grid of continuously measuring sensors. Rainfall simulation experiments with dye tracers while continuously monitoring soil moisture response allows for visualization of flow processes in the unsaturated zone at these locations. Data was analyzed at different spacio-temporal scales using various graphical methods, such as space-time colour maps (for the event and plot scale) and binary indicator maps (for the long-term and hillslope scale). Annual dynamics of soil moisture and decimeterscale variability were also investigated. The proposed approach proved to be successful in the investigation of flow processes in the unsaturated zone and showed the importance of preferential flow in the Malalcahuello Catchment, a datascarce catchment in the Andes of Southern Chile. Fast response times of stream flow indicate that preferential flow
\end{abstract}

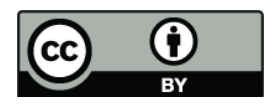

Correspondence to: T. Blume (blume@gfz-potsdam.de) observed at the plot scale might also be of importance at the hillslope or catchment scale. Flow patterns were highly variable in space but persistent in time. The most likely explanation for preferential flow in this catchment is a combination of hydrophobicity, small scale heterogeneity in rainfall due to redistribution in the canopy and strong gradients in unsaturated conductivities leading to self-reinforcing flow paths.

\section{Introduction}

Identification of patterns of soil moisture response to rainfall and especially the vertical dynamics of soil moisture at the hillslope or plot scale can be useful for the investigation of runoff generation processes in previously ungauged or data scarce catchments (runoff generation is here referring to all components of streamflow: groundwater, subsurface stormflow and surface runoff). When investigating runoff generation processes in a previously ungauged catchment it becomes obvious from the start that the equipment we are about to install is insufficient. There will be neither enough data points in time nor in space to characterize these processes in their temporal and spatial variability. A possible way to overcome this problem is the approach where a multitude of experimental methods is applied within a relatively short time frame, producing a data set that highlights a multitude of angles and aspects of catchment functioning. This type of study was carried out in the Malalcahuello Catchment in the Chilean Andes and is described in Blume et al. (2008a).

The hydrologic behaviour of young volcanic ash soils in Chile is little understood and no studies of high temporal

Published by Copernicus Publications on behalf of the European Geosciences Union. 
resolution soil moisture dynamics were found in our literature search. However, in other parts of the world such as New Zealand or Japan the soil moisture dynamics of volcanic ash soils has been investigated to some extent: Hasegawa (1997) used hourly TDR data to investigate soil water conditions and movement, Eguchi and Hasegawa (2008) used TDR and tensiometer data to estimate preferential flow, $\mathrm{Mu}-$ siake et al. (1988) used tensiometric observations and a numerical model to study infiltration and drying behaviour of these soils and Van't Woudt (1954) used 19 small lysimeters to investigate subsurface stormflow.

Soil moisture data has been used as a means to understand runoff generation in other parts of the world (e.g. Kienzler and Naef, 2007; Meyles et al., 2003; McNamara et al., 2005; Frisbee et al., 2007; Germann and Zimmermann, 2005; Zhou et al., 2002; Hino et al., 1988) or for the investigation of the effects of changes in land use or management on hydrological processes (Williams et al., 2003; Starr and Timlin, 2004). See also Robinson et al. (2008) and Vereecken et al. (2008) for comprehensive reviews on measurement techniques and the value of soil moisture data, respectively. In most studies soil moisture was measured either with high spatial or with high temporal resolution, thus producing either spatial soil moisture patterns (Bardossy and Lehmann, 1998; Brocca et al., 2007; Meyles et al., 2003; Williams et al., 2003; Western et al., 2004; Rezzoug et al., 2005; Nyberg, 1996) or information on the dynamics (e.g. McNamara et al., 2005; Starr and Timlin, 2004; Frisbee et al., 2007). A combination of both can only be achieved with either a large number of probes measuring continuously such as in Starr and Timlin (2004) and Taumer et al. (2006) or with geophysical methods such as described for example in Zhou et al. (2001), were electric resistivity tomography was used to investigate soil moisture dynamics on a $3.5 \times 3.5 \mathrm{~m}$ plot at hourly resolution. However, the first of these two options is cost-intensive while the second is predominantly carried out on grassland, fields or bare soils with little topography and is not feasible in complex terrain. Furthermore, as no general petrophysical relation to derive soil moisture from specific resistivity values is available, careful inversion and site specific calibration is needed. Combining data sets with different spatio-temporal resolution thus might be a viable cost-efficient alternative for difficult terrain. A recent study using a similar approach has been carried out in a small catchment in Australia, where 500 datapoints sampled on a weekly basis for 4 weeks were combined with 7 continuously measuring stations (Martinez et al., 2008).

At the Malalcahuello Catchment soil moisture was measured on two steep hillslope transects. Data was collected with a data logger at high temporal resolution at three points and manually at irregular intervals at 11 additional points. Each measurement produces soil moisture data for 6 different depths along a vertical profile. While this is still a very small number of data points it is nevertheless possible to get a general understanding of the major processes occur- ring within the unsaturated zone of this catchment. Data was analyzed using various graphical methods allowing for data exploration at different spatio-temporal scales. By carrying out rainfall simulation experiments using a dye tracer over each of the continuously measuring probes it was possible to corroborate our perception of flow in the unsaturated zone at these locations. This combination of high temporal resolution soil moisture measurements, rainfall simulation experiments and the use of dye tracers to reassess the conclusions gained from the soil moisture time series is noteworthy and has a high potential for synergetic effects. However, only one other study (Weiler and Naef, 2003) using a similar approach but a slightly different layout was found in our literature search. The study at the Malalcahuello catchment furthermore included the analysis of response times at the event scale, yearly soil moisture dynamics, spatial patterns and their long-term dynamics for 14 locations and 6 depths and the investigation of small scale soil moisture variability at the decimeter scale.

The four main questions of the study in the Malalcahuello Catchment were:

1. Can soil moisture data be used to investigate the dynamic patterns of unsaturated flow?

2. Can novel ways of data-visualization (e.g. space time colour maps) give a better picture of subsurface flow processes than traditional line plots alone?

3. Can the combination of data sets with different spatiotemporal resolution have synergetic effects and thus yield additional insights?

4. Can the observed soil moisture patterns and dynamics be connected with entire system/catchment response?

\section{Research area}

\subsection{The Malalcahuello catchment}

The research area is situated in the Reserva Forestal Malalcahuello, in the Precordillera of the Andes, IX. Region, Chile. The catchment is located on the southern slope of Volcán Lonquimay $\left(38^{\circ} 25.5^{\prime}-38^{\circ} 27^{\prime} \mathrm{S} ; 71^{\circ} 32.5^{\prime}-71^{\circ} 35^{\prime} \mathrm{E}\right)$. The catchment covers an area of $6.26 \mathrm{~km}^{2}$. Elevations range from $1120 \mathrm{~m}$ to $1856 \mathrm{~m}$ above sea level, with average slopes of $51 \% .80 \%$ of the catchment is covered with forest of the type Araucaria (Araucaria araucana) (with Lenga (Nothofagus pumilio) and Coigüe (Nothofagus dombeyi)) at higher elevations and Roble (Nothofagus obliqua) - Raulí (Nothofagus alpina) - Coigüe (Nothofagus dombeyi) at lower elevations. These types of native forest have a dense understorey of bamboo (Chusquea culeou). There is no anthropogenic intervention. Due to this dense vegetation interception losses 
Table 1. Soil physical characteristics for major horizons of the Trumao soils in the Malalcahuello Catchment. ( $K_{\text {sat-saturated hydraulic }}$ conductivity, GSD-grain size distribution, FC-field capacity, PWP-permanent wilting point, n.d.-not determined. Values are median values unless otherwise stated.)

\begin{tabular}{|c|c|c|c|c|c|c|c|}
\hline & & humus & horizon 1 & horizon 2 & horizon 3 & gravel & pumice \\
\hline color & & dark & dark brown & yellow brown & reddish brown & gray & orange \\
\hline occurrence & & common & common & common & less common & common & less common \\
\hline \multirow[t]{2}{*}{ depth range $(\mathrm{cm})$} & upper limit & 0 & 5-10 & $20-60$ & $25-90$ & $30-600$ & 60 \\
\hline & lower limit & $5-10$ & $20-60$ & $60-130$ & $45-170$ & $50-710$ & 90 \\
\hline \multirow[t]{4}{*}{$K_{\text {sat }}(\mathrm{m} / \mathrm{s})$} & $\min$ & $2.2 \mathrm{E}-04$ & $7.0 \mathrm{E}-05$ & $3.8 \mathrm{E}-05$ & $2.0 \mathrm{E}-05$ & $1.3 \mathrm{E}-03$ & $1.0 \mathrm{E}-03$ \\
\hline & $\max$ & $2.7 \mathrm{E}-03$ & $8.2 \mathrm{E}-04$ & $8.9 \mathrm{E}-04$ & $6.1 \mathrm{E}-03$ & $1.8 \mathrm{E}-03$ & $2.8 \mathrm{E}-03$ \\
\hline & median & $2.1 \mathrm{E}-03$ & $2.6 \mathrm{E}-04$ & $2.2 \mathrm{E}-04$ & $9.6 \mathrm{E}-05$ & $1.7 \mathrm{E}-03$ & $2.2 \mathrm{E}-03$ \\
\hline & No.of samples & 3 & 14 & 9 & 11 & 3 & 6 \\
\hline \multirow[t]{5}{*}{ GSD (mean \%) } & sand & n.d. & 69 & 67 & n.d. & 39 & n.d. \\
\hline & silt & n.d. & 29 & 30 & n.d. & 2 & n.d. \\
\hline & clay & n.d. & 2 & 3 & n.d. & incl. in silt & n.d. \\
\hline & gravel & n.d. & n.d. & n.d. & n.d. & 59 & n.d. \\
\hline & No.of samples & 0 & 2 & 14 & 0 & 6 & 0 \\
\hline \multirow[t]{4}{*}{ porosity (\%) } & $\min$ & 78 & 58 & 58 & 63 & 63 & 68 \\
\hline & $\max$ & 82 & 79 & 72 & 73 & 67 & 71 \\
\hline & median & 81 & 66 & 67 & 71 & 66 & 69 \\
\hline & No.of samples & 3 & 15 & 13 & 5 & 5 & 6 \\
\hline \multirow[t]{4}{*}{ bulk density } & $\min$ & 0.43 & 0.48 & 0.57 & 0.68 & 0.82 & 0.70 \\
\hline & $\max$ & 0.52 & 0.87 & 0.97 & 0.90 & 0.93 & 0.81 \\
\hline & median & 0.48 & 0.73 & 0.69 & 0.77 & 0.89 & 0.75 \\
\hline & No.of samples & 3 & 15 & 15 & 6 & 5 & 6 \\
\hline $\mathrm{FC}(\mathrm{Vol} \%)$ & at $0.33-0.06$ bar & $32-36$ & $33-43$ & $35-46$ & $32-39$ & $39-43$ & $22-26$ \\
\hline \multirow[t]{2}{*}{ PWP (Vol\%) } & at 15 bar & 10 & 16 & 24 & 20 & 24 & 15 \\
\hline & No.of samples & 3 & 15 & 9 & 9 & 5 & 6 \\
\hline
\end{tabular}

become significant: on average only $80 \%$ of total precipitation reaches the forest floor as throughfall (measured with a raster of throughfall collectors with a diameter of $10.5 \mathrm{~cm}$ ). However, throughfall amounts are highly variable and can in places also exceed total precipitation (measured outside the forest) by a factor of 2 or even 3 (Blume et al., 2008a). Above the tree line (20\% of the catchment area) there is no significant vegetation cover.

The soils are young, little developed and strongly layered volcanic ash soils (Andosols, in Chile known as Trumaos) (Iroumé, 2003; Blume et al., 2008a). High permeabilities (saturated and unsaturated), high porosities $(60-80 \%)$ and low bulk densities $\left(0.4-0.8 \mathrm{~g} / \mathrm{cm}^{3}\right)$ are typical for volcanic ash soils. They also usually show a strong hysteresis and irreversible changes (e.g. in water retention) with air-drying (Shoji et al., 1993). Soil hydraulic conductivities for the soils in the Malalcahuello catchment were determined for soil cores $(8 \mathrm{~cm}$ diameter) in the lab with the constant head method and range from $1.22 \times 10^{-5}$ to $5.53 \times 10^{-3} \mathrm{~m} / \mathrm{s}$ for the top $45 \mathrm{~cm}$ (independent of soil horizon), with an average of $5.63 \times 10^{-4} \mathrm{~m} / \mathrm{s}$ (42 samples). The mean conductivity for the fine gravel and pumice layers is $1.88 \times 10^{-3} \mathrm{~m} / \mathrm{s}(9 \mathrm{sam}-$ ples). Porosities for all horizons sampled range from $56.8 \%$ to $82.1 \%$. The mean porosity for the top $45 \mathrm{~cm}$ is $71.7 \%$ with a standard deviation of $6.6 \%$ (16 samples). Grain size distributions for the upper horizons resulted in an average of $66.5 \%$ sand, $30.4 \%$ silt and $3 \%$ clay. In the coarse layers the grain size fraction $\geq 2 \mathrm{~mm}$ ranges from $38-86 \%$ (Blume et al., 2008a). Layer thickness is also highly heterogeneous, and can range from $2-4 \mathrm{~cm}$ to several meters. It was not possible to establish a soil catena along the hillslope, probably due to the young age of the very little developed ash soils. For details on the soil physical characteristics of the major soil horizons in this catchment see Table 1. Depth to bedrock is unknown, however, manual augering to depths of $2-3 \mathrm{~m}$, at one occasion even $7 \mathrm{~m}$ was possible (Blume et al., 2008a). At the locations of the 4 wells at the lower end of this slope (Fig. 1) groundwater was found in depths of 1.8-3.2 m below the surface. However, at many other locations on this slope no groundwater was found in auger holes of similar depths. For a more detailed description of the Malalcahuello Catchment see Blume et al. (2008a).

The climate of this area can be described as temperate/humid with altitudinal effects. There is snow at higher elevations during winter and little precipitation during the summer months January and February. Annual rainfall amounts range from 2000 to over $3000 \mathrm{~mm}$, depending on elevation. 

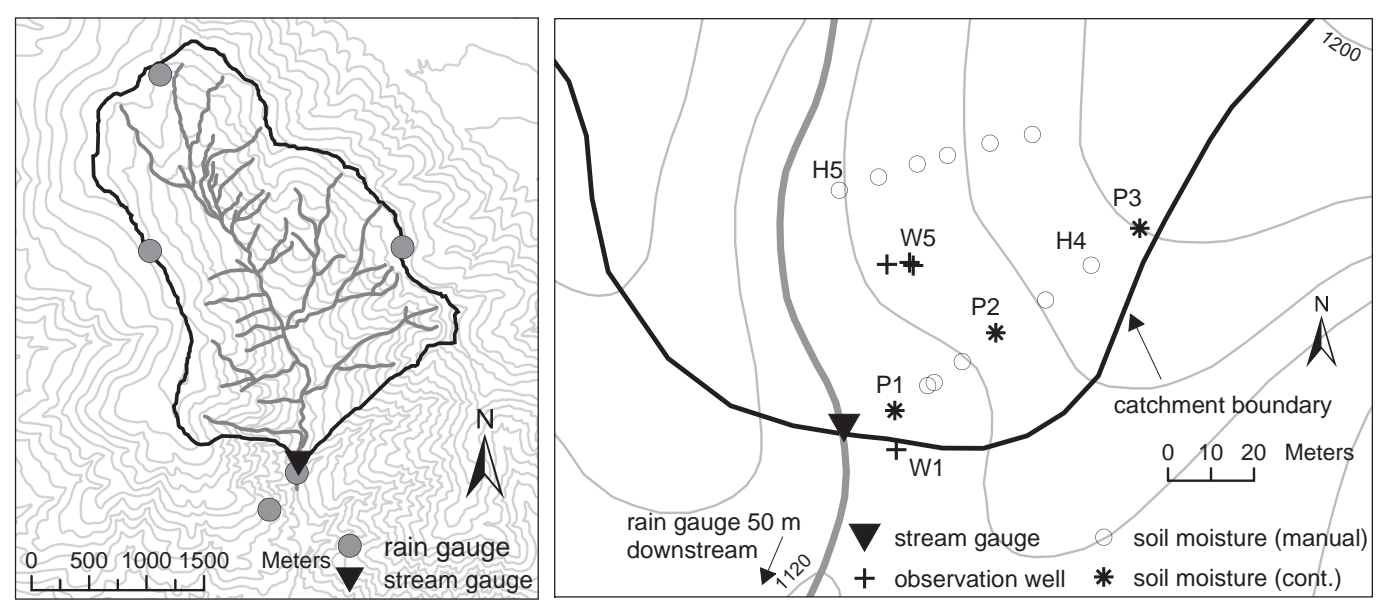

Fig. 1. Left: The Malalcahuello Catchment including the positions of rain gauges and the gauging station. The vertical resolution of the isolines is $50 \mathrm{~m}$. Right: The slope close to the catchment outlet. Shown are the positions of the continuously measuring soil moisture probes (P1-P3) as well as the locations of the manual soil moisture measurements. The position of the groundwater observation wells is also included. The vertical resolution of the isolines is $20 \mathrm{~m}$. H4 and H5 are exemplary manual measured moisture profiles for which data is shown in Sect. 4.3.

An overview of catchment layout and topography as well as instrumentation is given in Fig. 1.

The current perception of the hydrological processes in this catchment can be summarized as follows: Rainfallrunoff response is generally fast, in part due to high hydraulic conductivities and thus fast matrix flow. Lateral subsurface flow is assumed to be important as strongly differing soil layers offer interfaces either for flow along capillary barriers or impeding layers. Lateral flow has furthermore been observed in the duff layer during a high intensity rainfall simulation experiment (Blume et al., 2008b). A large subsurface storage is indicated by the deep unsaturated zone, the high porosities and the fact that event runoff coefficients are low, with 1$10 \%$ for 17 events analyzed in 2004/2005, of which a third are smaller than $2 \%$ (Blume et al., 2007), while yearly runoff coefficients $(>60 \%)$ as well as the baseflow index $(>75 \%)$ calculated for the years 2004 and 2005 are high (Blume et al., 2008a). Furthermore a shift in processes from dry to wet season (summer to winter) is indicated by a change in flow patterns observed through dye tracer experiments and a change in groundwater surface water interaction observed close to the catchment outlet (Blume et al., 2008b).

\section{Approach and methodology}

\subsection{Approach}

The approach of this study is based on the measurement of spatially scarce but high temporal resolution soil moisture profiles on the one hand and episodic and therefore temporally scarce soil moisture profiles on the other hand. These two datasets combined with additional experiments were used to investigate soil moisture response patterns and thus flow in the unsaturated zone. This included the analysis of yearly soil moisture dynamics as well as of event response patterns resulting in the deduction of flow processes, the use of rainfall simulation experiments with dye tracers to corroborate these deductions, but also the analysis of response times at the event scale. The episodic measurements along the hillslope transects allow for the analysis of spatial patterns and their long-term dynamics for 14 locations and 6 depths and for the investigation of small scale soil moisture variability at the decimeter scale. Figure 2 gives an overview of the data sets used in this study. The synergies arising from their combination are described in Sects. 4 and 5.

\subsection{Streamflow, groundwater levels and rainfall}

Water levels in stream and groundwater were measured with capacitive water level sensors (WT-HR Trutrack) at 5-10 min time intervals. Stream water levels were converted to discharge with the help of a rating curve and groundwater levels are reported in reference to the well datum or the datum of the stream gauge. Rainfall was measured with a tipping bucket rain gauge with a resolution of $0.27 \mathrm{~mm}$. A climate station maintained by the Universidad Austral de Chile is located in a nearby forest plantation at $1270 \mathrm{~m}$ elevation. This climate station has been logging the parameters rainfall, temperature, relative humidity, wind direction and velocity as well as global radiation at hourly intervals since 1999 . During the winter of 2005 an ultra-sonic snow height sensor was also installed at this climate station. For more details on the experimental methods applied in the Malalcahuello Catchment see Blume et al. (2008a). 


\begin{tabular}{|c|c|c|c|}
\hline resolution & datasets & results & \\
\hline LSHT & time series & & \\
\hline HSMT & binary maps & & \\
\hline HSMT & $\mathrm{dm}$ scale variability & & \\
\hline HSLT & dye tracer & & \\
\hline LSLT & hydrophobicity & & \\
\hline LSHT & event dynamics & & \\
\hline LSHT & dye tracer \& dynamics & & \\
\hline \multicolumn{4}{|l|}{ Legend } \\
\hline $\begin{array}{l}\text { higher } \\
\text { low ten } \\
\text { prefere } \\
\text { prefere }\end{array}$ & $\begin{array}{l}\text { than temporal variability } \\
\text { variability } \\
\text { ow } \\
\text { ow (inferred) }\end{array}$ & $\begin{array}{l}\text { persistent patterns } \\
\text { seasonal effects } \\
\text { seasonal effects (inferred) } \\
\text { fast response }\end{array}$ & $\begin{array}{l}\text { - confirmed by } \\
\text { - explained by }\end{array}$ \\
\hline
\end{tabular}

Fig. 2. Overview of data sets used in this study, along with their temporal and spatial resolution, main results and synergetic effects. (L-low, M-medium, H-high, S-spatial, T-temporal)

\subsection{Soil moisture profiles}

To investigate the dynamics as well as the trends in soil moisture profiles along the hillslope, measurements were carried out at two transects with FDR (frequency domain reflectometry) profile probes (Delta-T) in 10, 20, 30, 40, 60 and $100 \mathrm{~cm}$ depth. Both transects are located on the eastern slope close to the main stream gauging station S1 (Fig. 1). This hillslope was selected for being quite typical for the catchment in slope and vegetation as well as for its accessibility. At each depth soil moisture is measured in a soil volume of about $2500 \mathrm{ccm}$, a cylinder with a radius of $10 \mathrm{~cm}$. The absolute measurement error of about 3\% (as given by the manufacturer) is for the measurement of the dynamics of soil moisture of less importance. The error of the measured dynamics, i.e. the error of the values relative to each other is likely to be smaller than the absolute error. As a result of the special characteristics of the volcanic ash soil, such as the extremely high porosities and the fact that volcanic glass is a primary constituent, the built-in standard calibrations were not applicable. It was thus necessary to calibrate the probe specifically for this type of soil with gravimetrically determined water contents of 19 soil samples of the upper horizons (horizons 1 and 2 in Table 1), which generally cover depths from 5 to $130 \mathrm{~cm}$. Water contents for the calibration curve ranged from 16 to $51 \mathrm{Vol} \%$. The calibration resulted in a correction of the supplied generalised soil calibration given by the man- ufacturer: $\theta_{\text {corr }}=0.8126 \times \theta+0.1145$. With this calibration curve it was possible to reproduce the gravimetrically determined values with an $R^{2}$ of 0.94 and a median absolute error of only $1 \mathrm{Vol} \%$. These profile probes do not measure within a purely circular field as the sensor only extends about two thirds around the probe. For manual measurements it is possible to cover the full circle by taking three measurements, turning the probe by $120^{\circ}$ each time. While many of the soil cores used in the soil physical characterisation (Table 1) were taken at or close to this hillslope, there is no soil physical information available for the exact location of each of the sensors. Due to the large variability of layer thickness, it is also difficult to attribute the sensors to a specific soil horizon.

Three profile probes were connected to a data-logger and were measuring continuously with a temporal resolution of $10 \mathrm{~min}$. The data set extends from March 2003 to May 2006 for the lowest probe and from October 2004 to May 2006 for the two upper probes. For easier reference the three probes are numbered: probe 1 is located at the lower end and probe 3 at the upper end of the hillslope transect. A fourth probe was used for manual measurements at 11 points along the transects. 5 of these measurement locations supplement the transect of the continuously measuring probes, while the remaining 6 form a second transect located to the north of the first (Fig. 1). The points on the transects were roughly evenly spaced. These manual measurements were 
carried out at 41 occasions at irregular time intervals during field campaigns (December 2003-February 2004, October 2004-December 2004, November 2005-December 2005 and April-May 2006).

\subsection{Rainfall simulation experiments}

To investigate subsurface flow patterns 10 dye tracer experiments with brilliant blue were carried out in the Malalcahuello catchment in 2004 and 2005 (for details see Blume et al. (2008b)).

Furthermore, similar rainfall simulation experiments were conducted in May 2006 at the locations of the continuously measuring soil moisture probes. It was thus possible to test our perception of flow in the unsaturated zone at these profiles. The plot size was $1.2 \mathrm{~m} \times 1.2 \mathrm{~m}$ with the probe situated in the center. For all experiments the dye tracer Brilliant Blue with a concentration of $4 \mathrm{~g} / \mathrm{l}$ was used. The dye was applied with a hand pressurized pesticide sprayer in order to simulate rainfall. 301 of the dye were sprayed over a period of $3 \mathrm{~h}$. This corresponds to a total of $25 \mathrm{~mm}$ at application rates of $8.3 \mathrm{~mm} / \mathrm{h}$ on average. Profiles of the plots were excavated the following day and photos of the dye patterns were taken with a digital camera.

\subsection{Response times}

Response times were calculated for both, dry and wet season from the time series of rainfall, soil moisture, groundwater levels at well W1 (Fig. 1) and streamflow (all with $10 \mathrm{~min}$ resolution). Response time in this case was defined as the time period between begin of precipitation and first response of soil, ground- and stream water. The following threshold values were chosen to identify the point of first response in the time series: an increase of $0.2 \mathrm{Vol} \%$ in soil moisture, an increase of $0.005 \mathrm{~m}$ in groundwater level and an increase of $0.01 \mathrm{~m}^{3} / \mathrm{s}$ in stream flow. As the main interest are the relative changes in response times from winter to summer, the absolute values of these thresholds are of less importance as long as consistent thresholds (>noise of the time series) are used for the entire analysis.

\subsection{Data analysis}

Data was analyzed at different space-time scales using various graphical methods. The space-time scales analyzed included event and longterm scale, point and hillslope scale.

Simple line plots were used to analyze annual dynamics as well as small scale variability of soil moisture.

Soil moisture patterns at the hillslope scale are investigated with the help of binary indicator maps for each depth. These maps show locations where soil moisture is above/below a certain threshold. Here we selected the median value to indicate wetter/drier than average locations as well as the $75 \%$ quantile to indicat wet spots. These thresholds are calculated for each depth and sampling occasion at all sampling locations on both transects and depend thus on time and depth. The temporal aspect of these binary patterns is included in the indicator map by plotting location on the slope on the yaxis and time on the $\mathrm{x}$-axis, thus giving an idea of pattern persistency.

Event scale datasets with 10 min temporal resolution were analyzed with the help of colour maps which included temporal dynamics similar to those used by Weiler and Naef (2003). Here, time is plotted on the $\mathrm{x}$-axis while depth is plotted on the y-axis. Soil water content at each depth and point in time is visualized by color, changing from blue to red with increasing wetness. For additional information the response of streamflow and groundwater, as well as the rainfall intensity at each point in time were also included. Color scales were adapted from one event to the next in order to get the best "color resolution" possible, producing clearer patterns of response. It thus becomes possible to explore and identify patterns in moisture response, patterns in space and time that are much more difficult to identify in the classical line plots of soil moisture dynamics. In a next step flow processes were deduced from these patterns.

\subsection{Estimation of potential for self-reinforcing flow paths}

A rough estimation was used to investigate the potential of flow paths being self-reinforcing due to a strong gradient in moisture content: potential "flow within the flow path" was compared with "flow perpendicular to the flow path interface". The Van Genuchten parameters were obtained through fitting the Van Genuchten equation to the soil moisture characteristic curves. The soil moisture characteristic curves were determined with a pressure chamber for the first two horizons below the humus layer ( 3 samples each). These horizons are the two most commonly found soil layers which can extend to a depth of $130 \mathrm{~cm}$. Then the gradient in matric potential was determined from the soil moisture characteristic curves for different gradients in soil moisture. The Van Genuchten equation can then be used to determine the unsaturated conductivities for the chosen matric potential. A longitudinal distance of $10 \mathrm{~cm}$ was chosen, as this is the range of the soil moisture probes. The ratio of the gradients in potential (across interface/within flow path) was then compared with the ratio of the unsaturated hydraulic conductivities (within the flow path/across the interface). The effective unsaturated hydraulic conductivity across the flow path interface was calculated by treating the interface as two layers of differing conductivity (due to the differences in water content) and therefore using the harmonic mean for its calculation. The gradient in potential within the flow path is assumed to be equal to $1\left[\mathrm{~cm} \mathrm{H}_{2} \mathrm{O} / \mathrm{cm}\right]$. In case the ratio of the unsaturated hydraulic conductivities $\left(K_{\theta}\right)$ is much larger than the gradient in matric potential $(\Delta \psi)$ across the 
interface (Eq. 1), these flow paths are likely to persist over time.

$$
\frac{K_{\theta}(\text { flow path })[\mathrm{m} / \mathrm{s}]}{K_{\theta}(\text { interface })[\mathrm{m} / \mathrm{s}]} \gg \frac{\Delta \psi(\text { interface })\left[\mathrm{cm} \mathrm{H}_{2} \mathrm{O} / \mathrm{cm}\right]}{1\left[\mathrm{~cm} \mathrm{H}_{2} \mathrm{O} / \mathrm{cm}\right]}
$$

\subsection{Hydrophobicity}

Potential hydrophobicity was measured with the Water Drop Penetration Time (WDPT) test as described in Dekker and Ritsema (1994) for 12 air dried soil samples from 4 different locations and depths from 5 to $80 \mathrm{~cm}$. The WDPT test is a simple test for the persistency of water repellency where a water drop is applied to a soil sample and the time between application of the water drop and its penetration into the soil is measured. Water drop penetration times for air dried soil have been classified by Dekker and Ritsema (1994) into 5 classes: wettable $(<5 \mathrm{~s})$, slightly water repellent $(5-60 \mathrm{~s})$, strongly water repellent (60-600 s), severely water repellent (600-3600 s) and extremely water repellent (>3600s). After testing if a soil sample was wettable soil samples showing water repellency were submitted to 12 repetitions of the WDPT, each test carried out with a different subsample.

\section{Results and discussion}

\subsection{Annual dynamics of soil moisture}

The annual dynamics of soil moisture, shown for the period from October 2004-May 2006 in Fig. 3, are little pronounced in comparison to the event dynamics. Only during the summer months (February 2005 and February 2006) a short drying period can be observed (Fig. 3). However, as soon as the first rainfall starts in autumn, soil moisture values rebound to their previous level. Overall, the temporal variability of soil moisture at each of the sensors is much lower than the spatial variability along the depth profile (see also Blume et al. (2008a), for more detailed statistics on this topic). The profile at probe 1 (lowest on the slope) had generally higher moisture contents, but otherwise no trends along the transect could be established. Interestingly, events that lead to strong responses in discharge and groundwater level (e.g. in May and June 2005), do not show a comparably strong response in soil moisture (Fig. 3). As even the slope groundwater (well 5 - for location see Fig. 1) responds strongly, this difference in response can not be attributed to snow melt events in the upper part of the catchment. A more likely explanation is that the unsaturated subsurface in this catchment is close to equilibrium or steady state (see also the explanations to event 3 , in Sect. 4.4). This means that soil moisture change is close to zero, but waterflow itself is non-zero. Perturbations of rainfall and drought only lead to small and short responses in soil moisture as water is efficiently being transported to greater depths. While this efficient transport of water in the unsaturated zone only results in small changes in soil moisture in the upper meter, it also leads to a fast and pronounced response in ground and surface water.

Subsurface flow for the three events indicated with arrows in Fig. 3 is analyzed in more detail in Sect. 4.4.

\subsection{Soil moisture spatial patterns at the hillslope scale}

Using the manually measured soil moisture profiles as well as the corresponding logged data sets it was possible to establish a picture of spatial as well as coarse resolution temporal soil moisture characteristics. Soil moisture patterns at the two transects are depicted in Fig. 4 using the binary indicator maps.

Surprisingly, no general trends along the transects could be identified, apart from for the $10 \mathrm{~cm}$ sensors: There seems to be a correlation with position on the slope for the $10 \mathrm{~cm}$ depth, but not for the deeper sensors. At $10 \mathrm{~cm}$ depth the lower half of the slope is generally wetter than the upper part of the slope. This is probably due to shading effects: the deeper in the steep valley the fewer hours of direct sunshine. Another possible explanation is downslope flow accumulation in the o-horizon. The northern transect is wetter than the southern transect, which is probably due to denser vegetation. It was found that spatial patterns are generally persistent over time.

\subsection{Variability of soil moisture at the decimeter scale and preferential flow patterns}

Figure 5 shows the small scale variability in soil moisture measured by twisting the probes at the manual measurement points $\mathrm{H} 4$ and $\mathrm{H} 5$ (for location of these points see Fig. 1). Differences in soil moisture around the probe can be very pronounced, e.g. it is wetter/drier in one direction than in the others. These patterns of small scale variability are generally persistent over time while the temporal variability of soil moisture at this time resolution (irregular intervals during field campaigns) is generally low as the dynamics of response act on much shorter time scales (compare Fig. 2). It can be seen that while for measurement point $\mathrm{H} 4$ only the 20 and the $40 \mathrm{~cm}$ sensor show a stronger directional variability of $2.3 \mathrm{Vol} \%$ and $4.3 \mathrm{Vol} \%$, respectively, this phenomenon is found for all depths but the $100 \mathrm{~cm}$ level at location H5. Overall $68 \%$ of the sensors show directional variability (median variability $\geq 1.8 \mathrm{Vol} \%$ ) when counting each sensor along the probes separately (i.e. 6 depths times 11 locations). 29\% of all sensors have a variability $\geq 3 \mathrm{Vol} \%, 18 \%$ have a variability $\geq 4 \mathrm{Vol} \%$ and $6 \%$ show a variability of more than 5 Vol\%. As the profile probes have a range of only $10 \mathrm{~cm}$, this observed variability of soil moisture occurs on a very small scale, the scale of decimeters. A possible explanation for these strong gradients in water content over such a small distance is the presence of preferential flow patterns. This type of flow patterns was indeed found during a dye tracer 

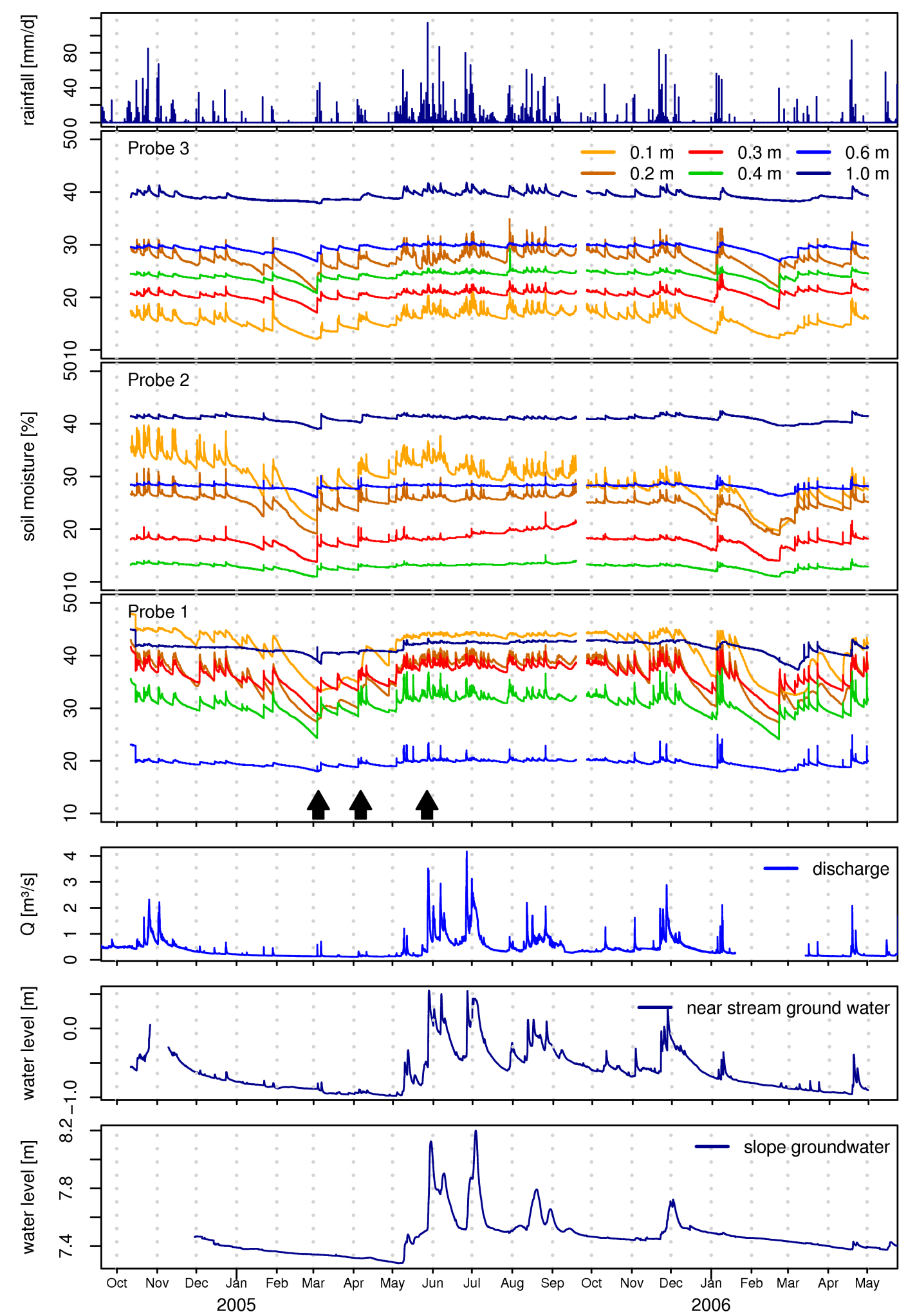

Fig. 3. Time series of rainfall, soil moisture, discharge and groundwater levels. The near stream groundwater levels correspond to well W1 and the slope groundwater levels to well W5 on Fig. 1. Groundwater levels are given in reference to the stream gauge. Maximum levels are about $1 \mathrm{~m}$ and $1.7 \mathrm{~m}$ below ground for W1 and W5, respectively. The black arrows indicate the timing of events analysed in Sect. 4.4 . 


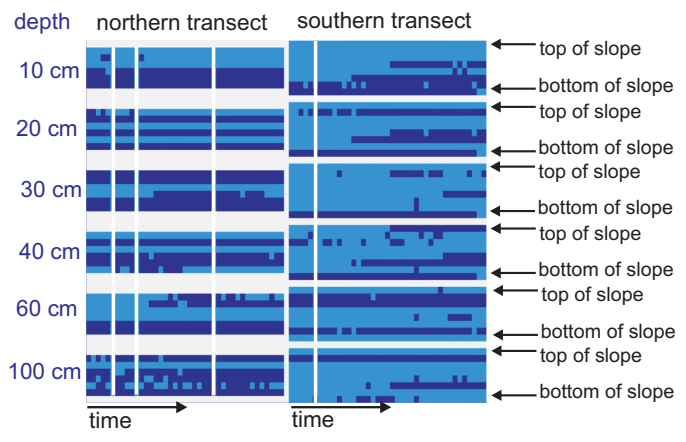

a) Soil moisture pattern with threshold = median

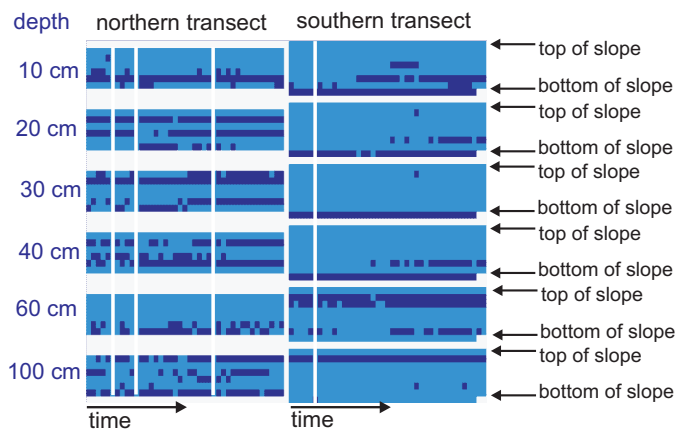

b) Soil moisture pattern with threshold $=75 \%$ quantile

Fig. 4. Manual soil moisture measurements at irregular intervals at 41 occasions during the field campaigns (December 2003-February 2004, October 2004-December 2004, November 2005-December 2005 and April-May 2006). The northern transect is shown on the left, the southern transect is shown on the right. Each block corresponds to one depth on that particular slope. Sensors are ordered as follows: lowest sensor on the slope is plotted on the lowest line of a single block. On the left transect there are 6 sensors, on the right transect there are 8 sensors. $y$ axis is position on the slope (within bars) and depth (from one bar to the next), $x$ axis is time (i.e. the 41 temporally irregularly spaced data points). Dark blue indicates measurements of soil moisture above the median (a) or the $75 \%$ quantile (b) of that depth, light blue are values below these thresholds. Missing data is indicated with white fields.

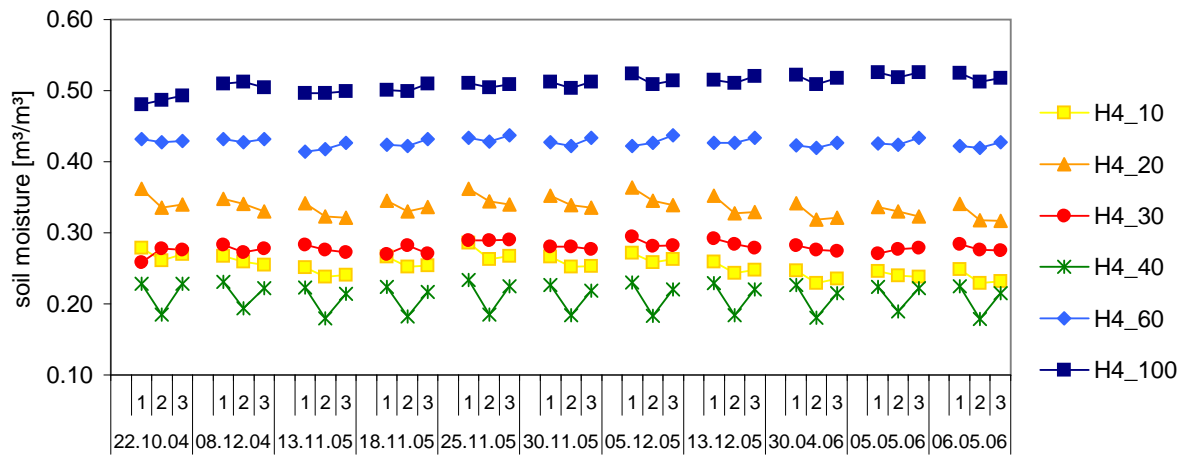

a) $\mathrm{H} 4$

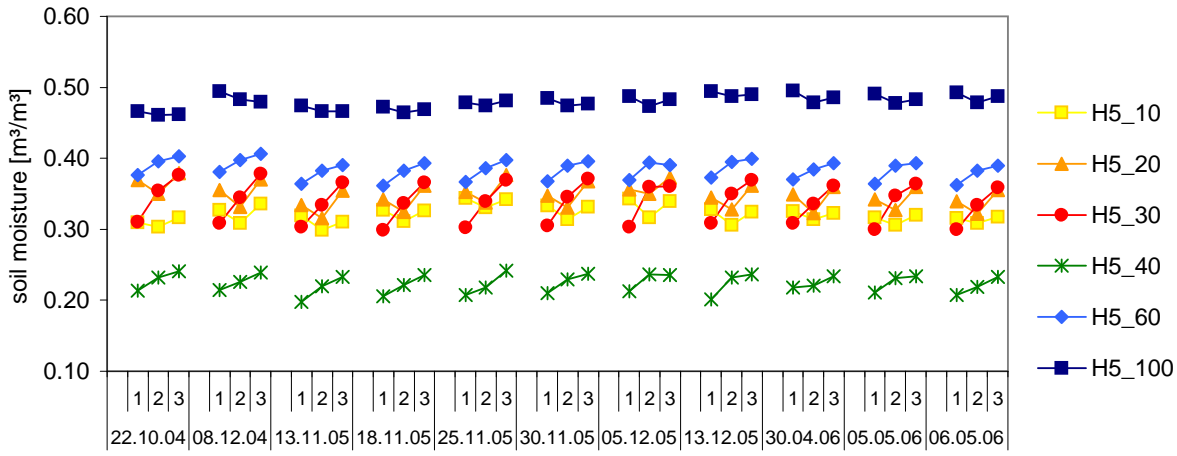

b) $\mathrm{H} 5$

Fig. 5. Directional or small scale variability at manual measurement points $\mathrm{H} 4$ and $\mathrm{H} 5$. Measurements $1,2,3$ at each date are repetitions within the same access tube, after rotating the probe by $120^{\circ}$. Measurement 1 is carried out with the sensor directed upslope, while for measurements 2 and 3 the sensor is angled downslope to the right and left, respectively. Note that the measurements are taken at irregular time intervals. 
Table 2. Results of the Water Drop Penetration Time (WDPT) test. If a sample showed water repellency the WDPT test was carried out with 12 repetitions, i.e. with 12 sub-samples. Shown are the number of tests per sample falling in the different classes of water repellency. Samples "forest 1-3" were taken at the slope of the soil moisture transect, while samples named "pine" were taken in a pine plantation downstream of the catchment outlet. The sampling sites of "forest 1-3" do not correspond to the locations of the soil moisture probes 1-3.

\begin{tabular}{|c|c|c|c|c|c|c|}
\hline location & $\begin{array}{l}\text { depth } \\
(\mathrm{cm})\end{array}$ & wettable & $\begin{array}{c}\text { slightly } \\
\text { water repellent }\end{array}$ & $\begin{array}{c}\text { strongly } \\
\text { water repellent }\end{array}$ & $\begin{array}{c}\text { severely } \\
\text { water repellent }\end{array}$ & $\begin{array}{c}\text { extremely } \\
\text { water repellent }\end{array}$ \\
\hline forest 1 & $5-10$ & no & - & - & 5 & 7 \\
\hline forest 1 & $10-15$ & no & - & 2 & 3 & 7 \\
\hline forest 2 & $10-20$ & no & - & 12 & - & - \\
\hline forest 2 & $20-60$ & yes & - & - & - & - \\
\hline forest 2 & $60-80$ & yes & - & - & - & - \\
\hline forest 3 & $10-20$ & no & 3 & 9 & - & - \\
\hline forest 3 & $20-60$ & yes & - & - & - & - \\
\hline forest 3 & $60-80$ & yes & - & - & - & - \\
\hline pine & $0-5$ & no & - & - & - & 12 \\
\hline pine & $5-20$ & no & 12 & - & - & - \\
\hline pine & $20-60$ & yes & - & - & - & - \\
\hline pine & $60-80$ & yes & - & - & - & - \\
\hline
\end{tabular}

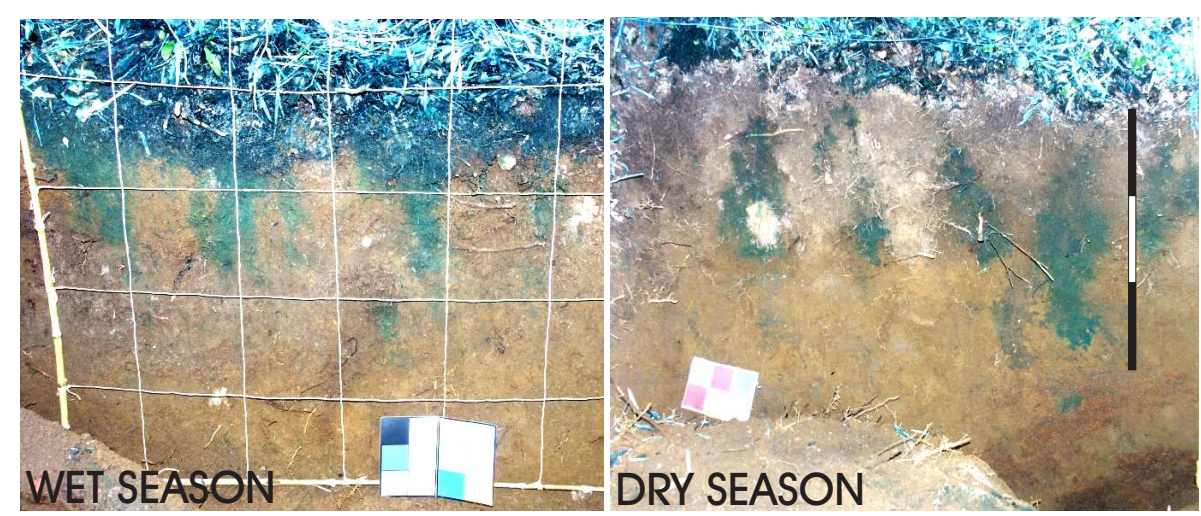

Fig. 6. Preferential flow paths marked during dye tracer experiments. Flow patterns differ from wet to dry season, especially in the top $20 \mathrm{~cm}$. For details see Blume et al. (2008b).

study in this catchment (Blume et al., 2008b), where preferential flow proved to be the rule for all forested sites ( 9 experiments), with slightly varying flow patterns during dry and wet season (Fig. 6). If a soil moisture sensor was located near the interface of such a preferential flow path, soil moisture would differ considerably depending on the direction of the measurement. The scale or width of the flow paths identified with the dye tracer is in the order of $<3$ decimeters, thus matching the scale of the measurement. A sensor showing no directional variation must therefore be located either in the center of a flow path or in the center of the matrix with no flow path within reach of the measurement. Ritsema and Dekker (1996) also used small scale $(5-10 \mathrm{~cm})$ variability of soil moisture as a measure for preferential or finger flow. In their study moisture gradients between flow paths and non-flow areas ranged between 3 and 6 Vol\%. Assuming small scale soil moisture variability does indeed indicate the presence of a preferential flow path, the fact that in Malalc- ahuello $68 \%$ of all sensors show this type of variability also gives us a measure of the importance of preferential flow in this catchment.

There are five possible explanations for the surprising persistency of the small scale soil moisture patterns (or preferential flow patterns) over the course of more than one and a half years (Fig. 5):

1. These patterns might be caused by air gaps between access tube and the surrounding soil due to faulty installation. However, special care was taken to avoid this problem, by using the auger supplied by the manufacturer of the probes. Furthermore no noticeable air gaps were found during excavation of the probes at the end of the field study, on the contrary, probes were sitting tightly in the soil. Air gaps are also likely to cause low soil moisture readings, but small scale variability was also found at higher moisture contents (Fig. 5) 
Table 3. Response characteristics and antecedent conditions for the three events shown in Fig. $7\left(P_{\text {tot }}=\right.$ rainfall amount, $P_{\text {Int }}=$ maximum rainfall intensity, antec. $\theta=$ antecedent mean soil moisture content for the top $30 \mathrm{~cm}$, max. $\Delta \theta=$ max. increase in soil moisture of all sensors, antec. $\mathrm{Q}=$ antecedent streamflow, max. $\Delta \mathrm{Q}=$ max. increase in streamflow, antec.GW= antecedent groundwater level at well $\mathrm{W} 1 \mathrm{relative}$ to the well datum at $2.55 \mathrm{~m}$ below the soil surface, max. $\Delta \mathrm{GW}=$ max. rise in groundwater levels).

\begin{tabular}{ccccccccc}
\hline Date & $\begin{array}{c}\mathrm{P}_{\text {tot }} \\
(\mathrm{mm})\end{array}$ & $\begin{array}{c}\mathrm{P}_{\text {Int }} \\
(\mathrm{mm} / 10 \mathrm{~min})\end{array}$ & $\begin{array}{c}\text { antec. } \theta \\
(\mathrm{Vol} \%)\end{array}$ & $\begin{array}{c}\max . \Delta \theta \\
(\mathrm{Vol} \%)\end{array}$ & $\begin{array}{c}\text { antec.Q } \\
\left(\mathrm{m}^{3} / \mathrm{s}\right)\end{array}$ & $\begin{array}{c}\max . \Delta \mathrm{Q} \\
\left(\mathrm{m}^{3} / \mathrm{s}\right)\end{array}$ & $\begin{array}{c}\text { antec.GW } \\
(\mathrm{m})\end{array}$ & $\begin{array}{c}\max . \Delta \mathrm{GW} \\
(\mathrm{m})\end{array}$ \\
\hline $03 / 03 / 2005$ & 52 & 8.6 & 21.6 & 8.6 & 0.13 & 0.45 & 0.08 & 0.11 \\
$06 / 04 / 2005$ & 28 & 1.6 & 26.8 & 3.8 & 0.13 & 0.06 & 0.01 & 0.03 \\
$27 / 05 / 2005$ & 124 & 3.2 & 29.1 & 5.5 & 0.29 & 3.22 & 0.42 & 1.20 \\
\hline
\end{tabular}

2. They might also be due to textural differences. However, as the sensors have only a range of $10 \mathrm{~cm}$ the measured volume is likely to be located within a single layer.

3. These patterns might also be induced by roots, which are not likely to change position on this time scale. However, roots were only found in some of the instances where these preferential flow patterns were observed during dye tracer experiments.

4. They might be due to hydrophobicity in some parts of the soil, which would produce self reinforcing patterns likely to persist if not subjected to long periods of saturation. The change in flow patterns from dry to wet season, which was found in the dye tracer experiments (Fig. 6, for details see Blume et al., 2008b), supports this theory (Fig. 2). Potential water repellency of soil samples from 5 to $80 \mathrm{~cm}$ depth was tested with the Water Drop Penetration Time test. It was found that while the top horizons show strong to extreme potential water repellency, samples from greater depths are wettable (Table 2). However, this test determines only potential water repellency, measured in air dried soil. Hydrophobicity under field conditions is likely to be less pronounced and spatially heterogeneous as a result of water redistribution by canopy, litter, microtopography or by variability in soil organic matter (Dekker and Ritsema, 1994; Ritsema and Dekker, 1995). The O-horizon in this catchment only has a thickness of about $5 \mathrm{~cm}$, but due to its higher organic matter content, it is likely to enforce redistribution processes due to spatially heterogeneous water repellency.

5. These patterns could also be self reinforcing due to the strong gradient in soil moisture itself, leading to faster vertical transport within the wetter area (the flow path) than lateral flow into the drier area as a result of the gradient in matric potential.

Possibility no. 5 was investigated with a simple estimation: If the ratio of the of the unsaturated hydraulic conductivities is much larger than the gradient in matric potential across the interface (Eq. 1), flow paths are likely to be self-reinforcing and persistent over time. This estimation was carried out by calculating the unsaturated conductivities for a number of gradients in soil moisture and thus matric potential: from 20 to $25 \mathrm{Vol} \%$, from 25 to $30 \mathrm{Vol} \%$ and from 30 to $35 \mathrm{Vol} \%$, thus covering the range from 20 to $35 \mathrm{Vol} \%$ of soil moisture, where most of the variability was observed. The gradient of $5 \mathrm{Vol} \%$ chosen to investigate this phenomenon was in the upper range of gradients observed in the field.The gradient in potential within the flow path is assumed to be equal to $1\left[\mathrm{~cm} \mathrm{H}_{2} \mathrm{O} / \mathrm{cm}\right]$. It was found that flow paths would indeed be self-reinforcing for a pure sand (with a ratio of $K_{\theta}$ up to 11 times larger than the ratio of $\Delta \psi$ ), however, in these ash soils, which have a fraction of at least $20 \%$ silt, it is very difficult to achieve these conditions (the ratio of $K_{\theta}$ is less than half that of the ratio of $\Delta \psi$ ). It is thus unlikely that solely the gradient in soil moisture causes the flow paths to persist in time. Nevertheless, if the unsaturated conductivity across the interface is further diminished by the effects of hydrophobicity a persistant pattern becomes more probable. Furthermore this type of soil is known to be hysteretic (Shoji et al., 1993; Musiake et al., 1988) thus causing a shift in the wetting curve compared to the here used draining curve, which could also change the outcome of this rough estimation. Persistent fingers as a result of hysteresis of the soil moisture characteristic curves were described by Selker et al. (1996) and Nieber (1996). Nieber (1996) explains that fingers will persist if the water entry pressure on the main wetting curve is smaller then the air entry pressure on the main drainage curve. However, due to lack of information on the main wetting curve, this effect cannot be assessed for the soils in the Malalcahuello Catchment.

\subsection{Soil moisture dynamics on event basis}

The soil moisture response was analyzed with the help of space-time colour maps for 34 rainfall events during the period from December 2004 to December 2005. The temporal resolution of these plots is $10 \mathrm{~min}$. Rainfall amounts for the events analyzed ranged from $16-150 \mathrm{~mm}$ ( 2 day periods) with a median value of $48 \mathrm{~mm}$. Maximum rainfall intensities ranged from $0.5-8.6 \mathrm{~mm} / 10 \mathrm{~min}$ with a median value of $2 \mathrm{~mm} / 10 \mathrm{~min}$. 


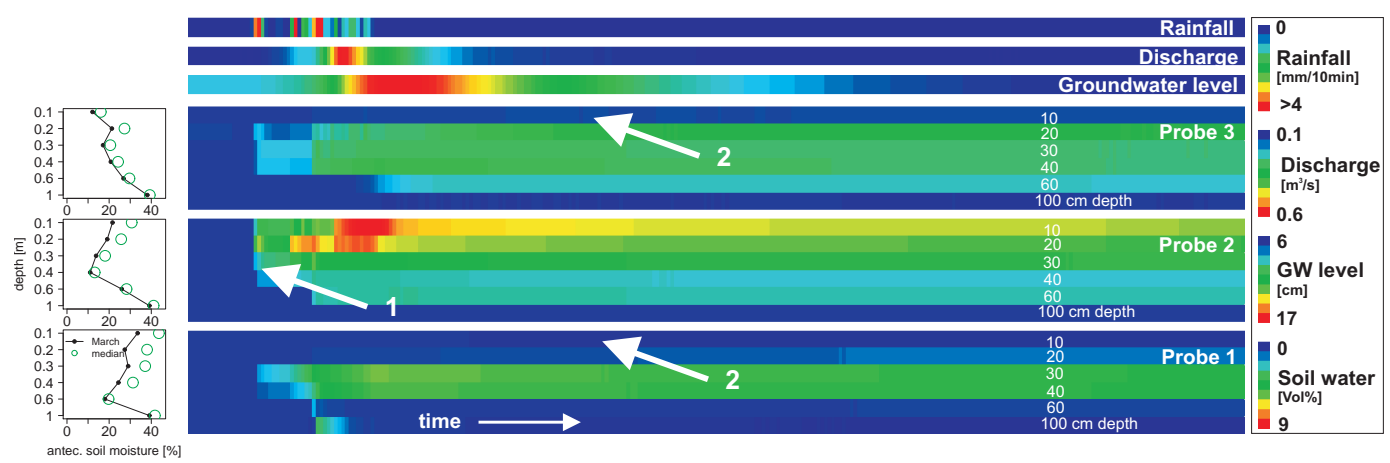

a) Rainfall event 3 March 2005 .

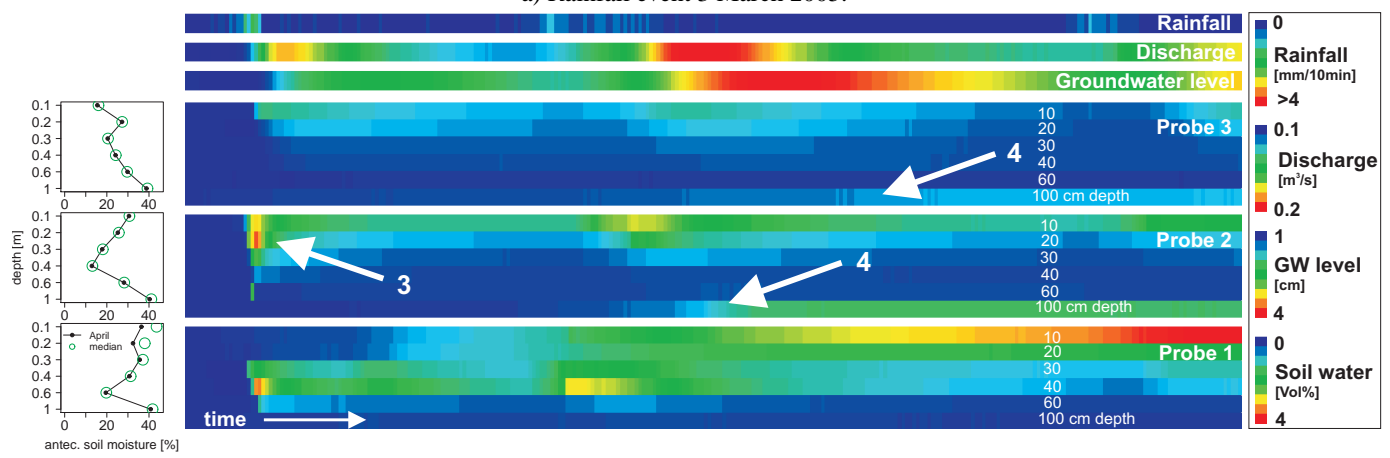

b) Rainfall event 6 April 2005 .

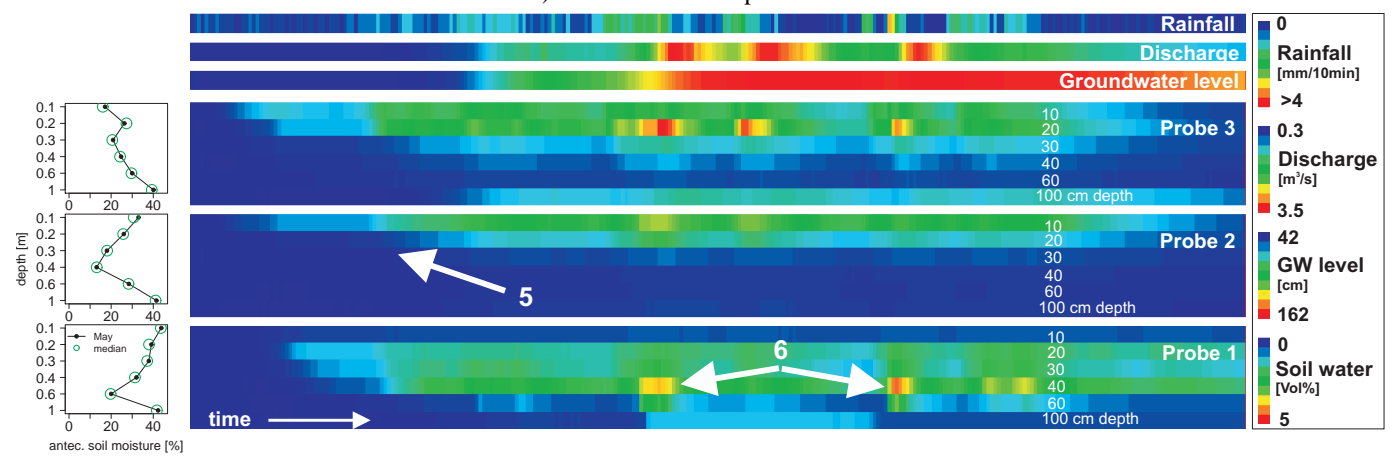

c) Rainfall event 27 May 2005 .

Fig. 7. Event response patterns of soil moisture for three rainfall events. Time is plotted on the x-axis. All plots show a two day period. Explanation of color bars from top to bottom: The uppermost bar shows 10-min rainfall intensity: dark blue is equivalent to $0 \mathrm{~mm} / 10 \mathrm{~min}$, dark red is equivalent to $\geq 4 \mathrm{~mm} / 10 \mathrm{~min}$. The two following bars show the increase of discharge and rise of groundwater level (at well W1), respectively. The color scale is stretched from minimum to maximum values. Down below follow the three wide bars representing the soil moisture response at the hillslope transect. The upper bar corresponds to the profile probe at the upper end of the slope (P3), the middle bar to the mid-slope probe (P2) and the lowest bar to the profile probe at the lower end of the slope (P1). Within these three wide colour bars, each stripe corresponds to a certain depth: $10,20,30,40,60$ and $100 \mathrm{~cm} .0$ on the soil water color scale corresponds to antecedent moisture content. The arrows indicate the most prominent features and are numbered for easier reference. The small plots to the left of each soil moisture bar show antecedent moisture conditions for each depth as well as the median values of soil moisture content as reference.

Three typical events are shown in Fig. 7. The timing of the events is indicated by arrows in Fig. 3. Probe 1 is located at the lower end and probe 3 at the upper end of the hillslope transect. Details of event response and antecedent conditions are listed in Table 3.

For the first event, the event on 3 March 2005 (Fig. 7a), total precipitation amounted to $52 \mathrm{~mm}$ with a highest inten- sity of $8.6 \mathrm{~mm} / 10 \mathrm{~min}$. The maximum change in soil moisture was high with $8.6 \mathrm{Vol} \%$, which is due to the fact that this event was the rainfall event with the lowest antecedent moisture content of all events studied (Moisture contents for depths 10,20,30 and $40 \mathrm{~cm}$ are below their median values for all three probes). The most prominent patterns found for this event are a) extremely fast vertical water transport (arrow 


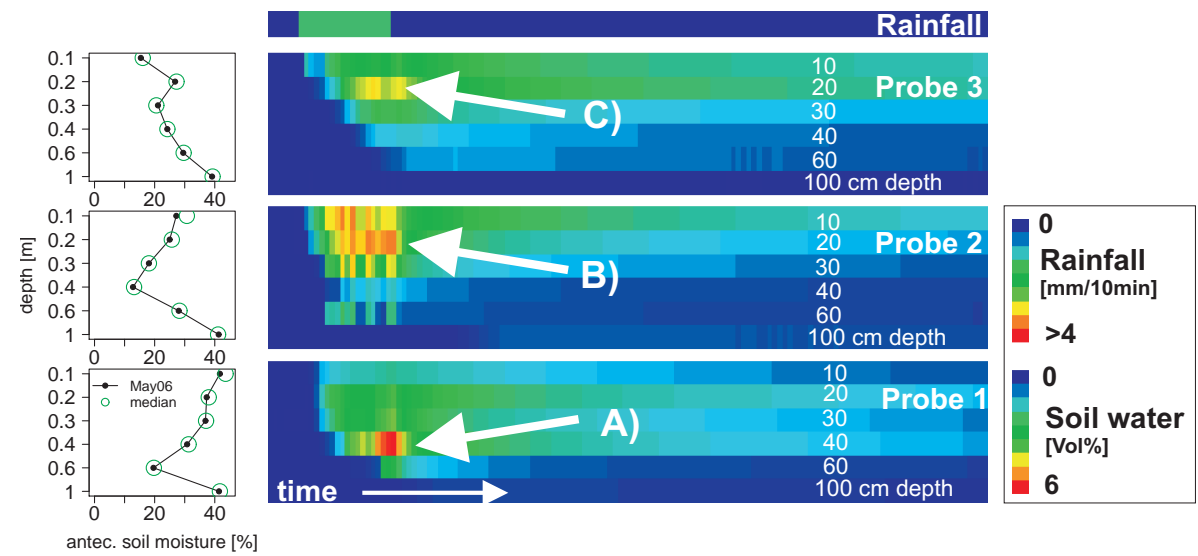

Fig. 8. Rainfall simulation with dye tracer at the locations of the soil moisture probes: amount of dye applied: $25 \mathrm{~mm}$, intensity of application: $8.3 \mathrm{~mm} / \mathrm{h}$. The arrows A, B and C mark the most prominent patterns observed during this simulated rainfall event. The time scale of this plot has a length of one day.

1 in Fig. 7a), due to high rainfall intensities and high hydraulic conductivities, and b) very little reaction at the $10 \mathrm{~cm}$ depth for probes 1 and 3 (arrow 2 in Fig. 7a). This is probably due to hydrophobicity resulting from the dry antecedent moisture conditions. This pattern was observed only for the 3 driest occasions. The dry antecedent conditions also make steady state conditions unlikely, where flow without change in moisture content is possible. Soil moisture increase below the hydrophobic layer thus must be due to lateral inputs, either at the the decimeter scale or at the hillslope scale.

The rainfall event on April 6th 2005 (Fig. 7b) has a total precipitation of $28 \mathrm{~mm}$ and only low rainfall intensities. The maximum increase in soil moisture, as well as streamflow and groundwater levels are low with $3.8 \mathrm{Vol} \%, 0.06 \mathrm{~m}^{3} / \mathrm{s}$ and $3 \mathrm{~cm}$, respectively (Table 3 ). Antecedent moisture contents correspond to the median values for most depths, apart from the 10 and $20 \mathrm{~cm}$ depths at probe 1 . The major patterns identified for this event are: a) fast vertical water transport, due to high hydraulic conductivities (arrow 3 in Fig. 7b), and b) late but persistent response at $100 \mathrm{~cm}$ depth for probes 2 and 3 , while no such reaction can be seen at the $60 \mathrm{~cm}$ sensor (arrow 4 in Fig. 7b). As water is apparently not transported to this point vertically, this seems to be the result of lateral water input, causing a slow trailing "wave" at this depth.

The event on 27 May 2005 (Fig. 7c) has a very high total precipitation of $124 \mathrm{~mm}$ with a highest intensity of $3.2 \mathrm{~mm} / 10 \mathrm{~min}$. However, as this event is probably a rain on snow event, it is difficult to estimate the actual amount of water entering the soil. Antecedent moisture contents are high (at or above median values). While the response of discharge $\left(3.22 \mathrm{~m}^{3} / \mathrm{s}\right.$ increase $)$, and ground water levels $(120 \mathrm{~cm}$ increase) is extremely strong, soil moisture shows a much less pronounced reaction. One possible explanation is that this is not only an event with high rainfall amounts, but that snow was also present in the catchment at this time $(30 \mathrm{~cm}$ of snow were measured at the climate station just outside of the research catchment at $1270 \mathrm{~m}$ elevation, while the soil moisture transect is located at about $1140 \mathrm{~m}$ elevation.). Therefore some of the runoff might be generated at the snow surface or within the snow layer. However, the extreme response at well W5 (see also Fig. 3) proves that large amounts of water did indeed enter the subsurface. A more likely explanation is therefore that as all water in excess of field capacity is being transported quickly to greater depths, soil moisture increases most for dry antecedent conditions and less in conditions of high antecedent wetness despite the fact that large amounts of water are being transported during nearly steady state flow conditions. This efficient vertical water transport will result in a pronounced response in the saturated zone without causing similarly pronounced peaks in moisture content. The most prominent patterns for this event are: a) slow vertical water transport, probably due to lower rainfall intensities (arrow 5 in Fig. 7c and b) strong response at $40 \mathrm{~cm}$ depth for probe 1, very local and short-term (arrow 6 in Fig. 7c). This reaction might be due to an underlying capillary barrier, causing the water to pond above it until breakthrough. This pattern was observed at this location quite frequently (for 15 events out of 34).

\subsection{Dye tracer rainfall simulation}

In May 2006 rainfall simulation experiments with blue dye were carried out at the locations of the three continuously measuring probes. The soil moisture dynamics of these three experiments are shown in Fig. 8, with space-time colour maps equivalent to Fig. 7. As the same amount of dye was applied over the same amount of time during each of these experiments, the three experiments are plotted in one single figure as if corresponding to a single rainfall event. The time period and intensity of dye application is plotted in the top bar. The same colour scale was applied for the intensity 


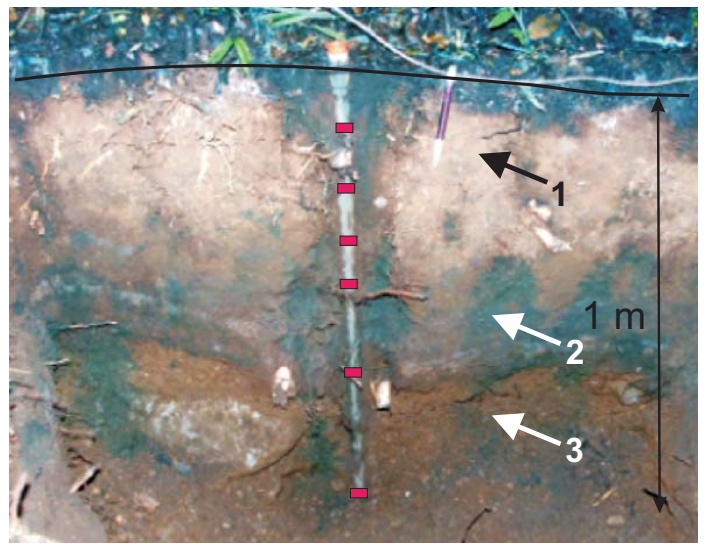

(a) Flow paths at profile probe 1

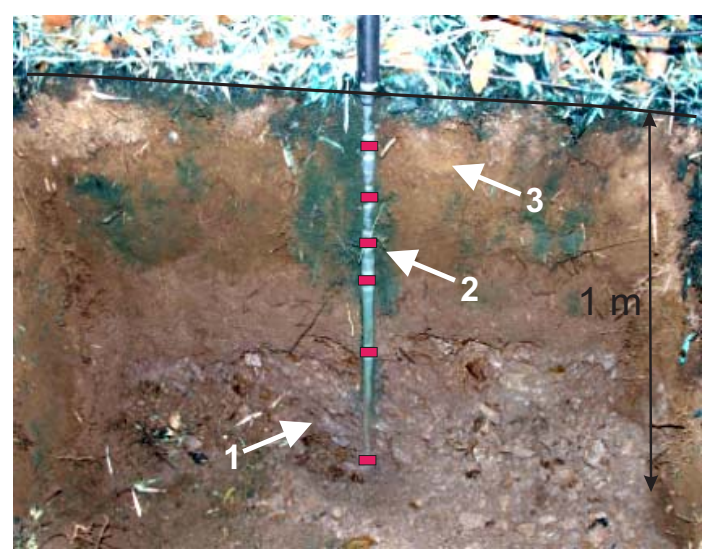

(b) Flow paths at profile probe 2

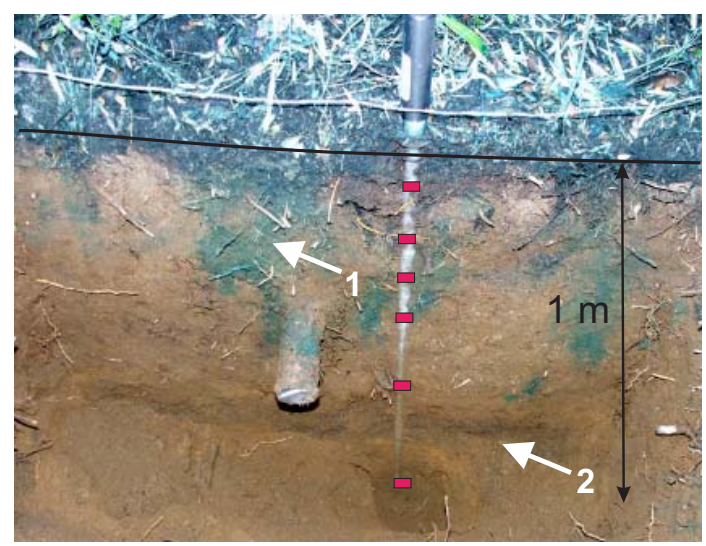

(c) Flow paths at profile probe 3

Fig. 9. Flow path visualization at the locations of the three continuously logging profile probes. The black line indicates the soil surface and the arrows the most important features in each photo. They are numbered for easier reference. The red lines indicate the approximate location of the soil moisture sensors.

of application as for the rainfall intensities in Fig. 7. Neither streamflow nor groundwater level dynamics are plotted as there was no reaction to these small scale experiments (small in comparison to the size of the hillslope). Antecedent moisture contents are quite high (at median values for all but the $10 \mathrm{~cm}$ sensors at probes 1 and 2). The dynamic moisture response patterns show fast/preferential vertical flow for probes 1 and 2 and slow vertical water transfer for probe 3 (Fig. 8). One day after the sprinkling experiment, cross sections of the infiltration plots were excavated and the dye stain patterns marking the flow paths of the dye in the unsaturated zone were photographed. The three photos of the cross sections at the locations of the soil moisture probes are shown in Fig. 9. Preferential flow is found at all three plots (compare Fig. 2). Flow occurred in plumes, which are separated by distinct areas of little or no flow unmarked by blue dye.

Figure 9a shows the flow paths of probe 1 (located at the bottom of the slope). While blue dye can be seen in the top $5 \mathrm{~cm}$, hardly any dye stains could be found in depths of 5- ca. $30 \mathrm{~cm}$ (arrow 1 in Fig. 9a). This is most likely the suspected zone of hydrophobicity which was also found in the analysis of the time-space maps of soil moisture response to rainfall events. This zone of hydrophobicity or water repellency is most pronounced after summer dry periods but is still visible at the time of the sprinkling experiment where only little reaction was seen at the $10 \mathrm{~cm}$ sensor of probe 1 (Fig. 8). Distinct plumes of dye can be found at depths of ca. $30-60 \mathrm{~cm}$ (arrow 2 in Fig. 9a) (also at the location of the soil moisture probe), just above a very pronounced layer interface between the silty sand layer above and the gravelly layer below (arrow 3 in Fig. 9a). This confirms the hypothesis that a capillary barrier could be the cause of the ponding at the $40 \mathrm{~cm}$ sensor which was seen in the event response analysis (Fig. 8, arrow A). The dye stains also indicated the locations were water leached into the capillary barrier (arrow 3 in Fig. 9a). The maximum depth of dye infiltration was about $1 \mathrm{~m}$. Probe 1 is thus intersecting a preferential flow path, which is in part due to roots and in part probably due to 
Probe 3

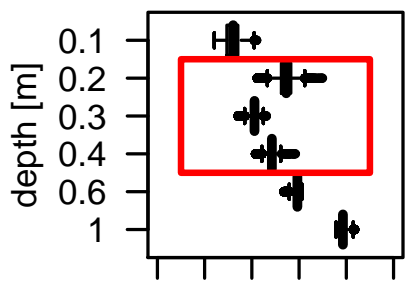

$\begin{array}{lll}0.0 & 0.2 & 0.4\end{array}$

soil moisture $\left[\mathrm{m}^{3} / \mathrm{m}^{3}\right]$

Probe 2

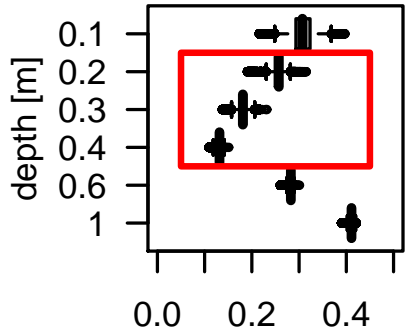

soil moisture $\left[\mathrm{m}^{3} / \mathrm{m}^{3}\right]$

Probe 1

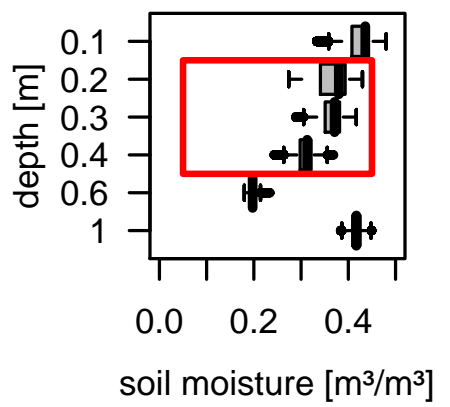

Winter: P3 ( $=19)$

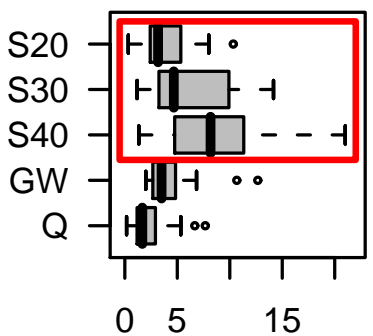

response lag [h]

Winter: P2 (n=19)

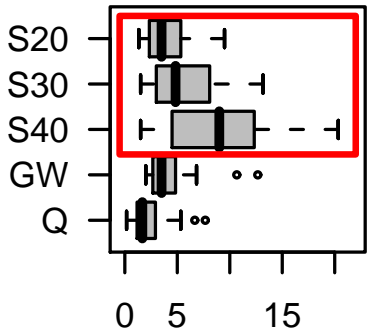

response lag [h]

Winter: P1 ( $\mathbf{n = 1 9 )}$

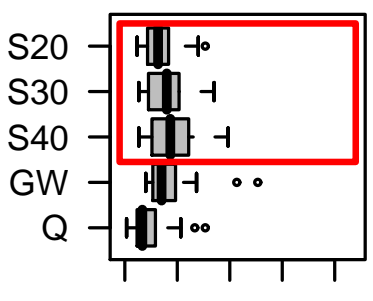

$\begin{array}{lll}0 & 5 & 15\end{array}$

response lag [h]
Summer: P3 ( $n=8)$

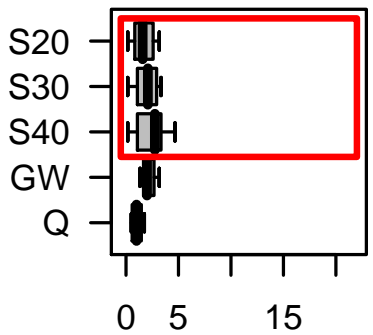

response lag [h]

Summer: P2 ( $\mathrm{n}=8)$

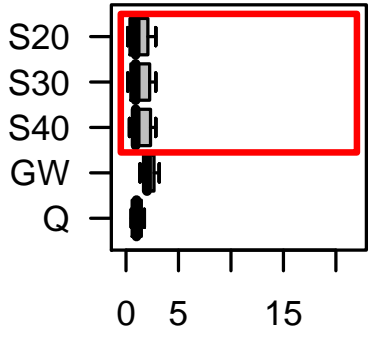

response lag [h]

Summer: P1 $(n=8)$

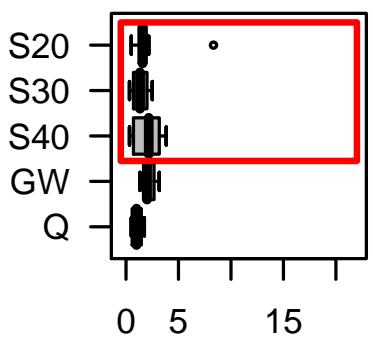

response lag $[\mathrm{h}]$

Fig. 10. Soil moisture variability along each profile as well as lag times of response in soil moisture, discharge (Q) and groundwater levels (GW) for 19 events in winter and 8 events in summer. Soil moisture response times are shown for 20, 30 and 40 cm depth (S20, S30, S40).

flow patterns caused by water repellency of the soil. In late summer the $10 \mathrm{~cm}$ and sometimes also the $20 \mathrm{~cm}$ sensor are surrounded by hydrophobic soil (Fig. 7a and b).

The cross section at probe 2 (Fig. 9b) shows as most distinct feature the saprolite layer (weathered bedrock) starting at the location of the $60 \mathrm{~cm}$ sensor (arrow 1 in Fig. 9b). The $100 \mathrm{~cm}$ sensor is thus located within the saprolite. It was also found that the probe is located within a preferential flow path coinciding with a concentration of fine roots (arrow 2 in Fig. 9b). Maximum infiltration depth is about $80 \mathrm{~cm}$ in the three major plumes. A hydrophobic layer with very little staining can be seen in the cross section (arrow 3 in Fig. 9b). However, this layer was not identified in the soil moisture data, as the probe is located within the preferential flow path and not in a hydrophobic patch. The high velocity of flow and the strong response in this preferential flow path is also visible in Fig. 8 (arrow B) and was also a feature of the soil moisture response space-time maps at this location.

The soil at probe 3 (Fig. 9c) differed compared to the two others as the vegetation at this plot included a thicket of low shrubs, causing a higher density of roots in the top $20 \mathrm{~cm}$ (arrow 1 in Fig. 9c). Here, the probe was located in between dye stained preferential flow paths. While blue dye is found in the vicinity of the probe at depths $10-20 \mathrm{~cm}$, very little of it is found close to the probe at greater depths. The $60 \mathrm{~cm}$ sensor is located just at the interface between the silty sand 
and a layer of fine gravel (arrow 2 in Fig. 9c), thus probably measuring in both layers, while the $100 \mathrm{~cm}$ sensor is situated in a layer of more compacted silty sand starting at a depth of approx. $75 \mathrm{~cm}$. Maximum depth of infiltration is $80 \mathrm{~cm}$. The fact that the layer at the $100 \mathrm{~cm}$ sensor is more compacted might explain why reaction at this sensor occurs delayed and prolonged. This would correspond to lower hydraulic conductivities in the compacted layer causing a delay in response and a prolonged peak. However, as the response at the $60 \mathrm{~cm}$ sensor is often very weak, the water causing the peak at $100 \mathrm{~cm}$ depths is most likely transported to this point not vertically but laterally. The dense root zone in the top $20 \mathrm{~cm}$ explains the strong reaction at the $20 \mathrm{~cm}$ sensor (Fig. 8, arrow C). Probe 3 shows a slower reaction to rainfall compared to the other two probes (Fig. 8 and also Fig. 7), which is explained by the fact that this probe is not situated within a preferential flow path.

\subsection{Response times}

To test if the seasonal change in subsurface flow has an effect on overall catchment response, response times for soil moisture, groundwater and stream flow were calculated for the wet and dry season separately (Fig. 10). This analysis is based on 27 rainfall events between December 2004 and April 2006. S20, S30, S40 are the response lags of the soil moisture sensors at 20,30 and $40 \mathrm{~cm}$ depth, GW is the response lag of ground water level at well W1 (Fig. 1) and Q is the response lag of stream flow. Groundwater response is generally slower than stream flow response. (At this hillslope the groundwater surface at well W1 in the vicinity of the stream is generally about $60 \mathrm{~cm}$ below the level of the stream bed.) Surprisingly, the soil moisture sensors often react slower than stream flow. This could either mean that rainfall is not uniformly distributed over the catchment or that these sensors are bypassed by preferential flow paths. Surface runoff is unlikely, due to high infiltration rates and porosities and has not been observed during field campaigns. Another possible explanation would be lateral flow in the duff layer/organic horizon. Response lags of all parameters show similar behavior over time: response times are short from January to April (summer and early fall) when compared to the winter months. This is probably the result of higher rainfall intensities on the one hand (median maximum intensities are $2.1 \mathrm{~mm} / 10 \mathrm{~min}$ in winter and $3.0 \mathrm{~mm} / 10 \mathrm{~min}$ in summer) and enhanced preferential flow due to hydrophobicity on the other hand. Snow was present/melting during 4 of the winter events, however, this does not lead to a consistent change in response time: both, faster and slower than median responses have been observed for these events. Streamflow response times for the events shown in the space-time colour maps (Fig. 7) range from 30 minutes for the first event (driest antecedent moisture conditions), 1:50 $\mathrm{h}$ for the second event up to $6: 40 \mathrm{~h}$ for the event in May (wettest antecedent conditions).

\section{Summary and conclusions}

The soil moisture data obtained in this study provided diverse insights in subsurface flow and runoff generation processes in this catchment. It was shown that high resolution time series of soil moisture in combination with manual measurements at irregular time intervals can be a valuable addition to time series of precipitation and discharge when investigating runoff generation processes. This is especially true for catchments where only short time series of data are available, as in the Malalcahuello Catchment. The approach of combining datasets with different spatio-temporal resolution allowed for the investigation of soil moisture dynamics as well as patterns and proved to be less expensive than high density installation of continuously logging sensors while also being applicable to difficult terrain, i.e. densely forested and steep hillslopes. The synergetic effects achieved with this combination of datasets is visualized in Fig. 2.

The time series of soil moisture for the 19 month period in Fig. 3 show that spatial variability of soil moisture is much higher than its temporal variability. Both, rainfall events and droughts only cause small, fast and short perturbations and the moisture content quickly rebounds to previous levels. This behaviour corresponds to a system at or close to a dynamic equilibrium, i.e. close to steady state flow conditions in the subsurface. This seems to prevail most time of the year. This is corroborated by the high annual precipitation, high baseflow index and annual runoff and the very low event runoff coefficients.

The use of space-time colour maps facilitated the analysis of soil moisture response dynamics, especially concerning the timing and extent of response along the vertical profile. It was thus possible to identify a number of patterns which can be attributed to different phenomena of flow in the unsaturated zone. The very subdued response of soil moisture in the upper soil horizon at two locations during the driest period (late summer) was attributed to the formation or reinforcement of hydrophobicity in this layer. The accumulation/ponding of water at certain depths was assumed to be due to the effect of capillary barriers. This was confirmed by the dye tracer experiment carried out at this location.

Strong response at certain depths while the layers just above show little reaction indicate the importance of lateral flow processes. However, we do not know on what scale these thus "observed" lateral flow paths are active (several decimeters, meters or hillslope scale). Lateral flow has also been directly observed in a dye tracer experimenet with an application intensity of $20 \mathrm{~mm} / \mathrm{h}$. Here lateral flow occurred in the duff layer (Blume et al., 2008b). The short response times of streamflow also indicate that lateral subsurface storm flow is likely to be important.

It was furthermore found that infiltration dynamics differed from summer to winter, which could be due to differences in rainfall intensities as well as the amplification of preferential flow due to hydrophobicity in the top layer. 
Persistency of potential water repellency was found to be strong to extreme for the upper horizon. Hydrophobicity has also been observed in Chilean young volcanic ash soils by other researchers (Bachmann et al., 2000; Ellies, 1975) and is also of importance in volcanic ash soils of Ecuador (Poulenard et al., 2004). In addition, differences in flow patterns from dry to wet period were found in the Malalcahuello Catchment during a more extensive study involving a total of 10 dye tracer experiments (Blume et al., 2008b). The change in flow pattern observed in this study further supports the theory that preferential flow in this catchment is reinforced by hydrophobicity (application intensities were the same for dry and wet season experiments). Similar flow patterns also attributed to hydrophobicity were observed in other studies (Ritsema and Dekker, 2000; Ritsema et al., 1998; Ritsema and Dekker, 1994; Dekker and Ritsema, 2000; de Rooij, 2000). The fact that throughfall amounts are highly heterogenous in this catchment (Blume et al., 2008a) is likely to be the reason why some locations (probably on the decimeter scale) are drier than others and thus more likely to develop water repellency. Spots of high water input are therefore likely to become preferential flow paths. These observed patterns in dynamics were found to be spatially and temporally persistent insofar as the event pattern dynamics of soil moisture observed in Fall 2005 (Fig. 7) matched well with the flow patterns found during the dye tracer experiments one year later. The persistency of the spatial patterns of soil moisture for 14 locations and 6 depths (Fig. 4) shows that spatial variability is much higher than temporal variability and that wetter locations are likely to remain wet. Furthermore the patterns of soil moisture variability at the decimeter scale, which were attributed to the presence/absence of preferential flow paths, were also found to be persistent over a period of more than one and a half years. The stationarity of these flow patterns is another indicator that steady state conditions prevail in this catchment.

Hydrophobicity is the most likely explanation for the flow patterns found here. However, the effects of hydrophobicity are probably aggravated by root channels, strong gradients in matric potential and the hysteresis of the soil moisture characteristic curves of volcanic ash soils as described by Shoji et al. (1993).

The last and maybe most important question is the question of how important this locally observed preferential flow is for the system as a whole, i.e. runoff response/runoff generation at the catchment scale.

The small response of soil moisture dynamics to perturbations as well as persistency/stationarity of flow paths corroborate our perception that this undisturbed, forested catchment is at or close to steady state, i.e. a dynamic equilibrium. This perception was originally based on integral observations such as the fact that we observe high annual runoff and a high baseflow index, while event runoff coefficients are low, and has now been corroborated by internal observations, e.g. soil moisture response and flow patterns. Efficient water trans- port, as observed locally, therefore would indeed have an effect at the catchment scale.

Several additional findings indicate that while preferential flow was only observed at the plot scale it might indeed be an important factor of runoff generation at the catchment scale. That preferential flow occurs throughout the catchment is indicated by the fact that additionally to the three tracer experiments shown in this study all 9 dye tracer experiments carried out under forest at various locations in the catchment showed preferential flow patterns (Blume et al., 2008b). The fact that $68 \%$ of the sensors at the 11 manual measurement points showed small scale soil moisture variability is another indicator for the importance of these preferential flow paths. Last but not least the analysis of response times for soil moisture, groundwater and streamflow reveiled that response lags are generally much shorter during the summer months were preferential flow is also likely to be further enforced by stronger hydrophobicity. Interestingly streamflow often shows faster response than both groundwater and soil water. This might be due to non-uniform rainfall distribution (i.e. earlier onset of rainfall further up in the catchment causing stream levels to respond while soil moisture at the slope close to the catchment outlet remained unchanged). However, as soil moisture response measurements are restricted to only three locations it is also likely that there are other preferential flow paths with even faster response than the ones measured by our instruments. In this case preferential flow in the vertical and then a fast reaction along a horizontal layer interface might be the reason for the short response lags of streamflow found in this catchment. (Finger flow is known to cause faster breakthrough as investigated by de Rooij and deVries (1996) in a modelling study.) The question whether or not these preferential flow processes are important for catchment response could be investigated further by application of a physically based hydrological model either on the hillslope or on the catchment scale.

To summarize the main conclusions in short:

1. the synergy of soil moisture datasets with different spatio-temporal resolution proved to be useful for the investigation of subsurface flow processes. Continuously monitored rainfall experiments at the location of the moisture probes with subsequent excavation of dye stained soil profiles facilitated testing/corroboration of the perception of subsurface flow gained from the moisture patterns.

2. data-visualization with space-time colour maps permits a much more detailed analysis of soil moisture response than simple line plots alone

3. soil moisture/flow patterns in the here investigated young volcanic ash soils were shown to be persistent in time and highly variable in space

4. the most likely explanation for the observed flow patterns is a combination of hydrophobicity with strong 
gradients in unsaturated conductivities, where flow paths are initiated either by the presence of roots or the highly heterogeneous distribution of throughfall and thus water input

5. this soil moisture data set has provided us with internal observations corroborating our perception that the catchment is at or close to steady state/dynamic equilibrium, which was originally based on integral data, mainly rainfall and runoff time series.

6. the flow patterns observed at the local scale are likely to be important for runoff response at the catchment scale.

Acknowledgements. The authors would like to thank A. Bauer, D. Reusser (Potsdam University) and H. Palacios, L. Opazo (Universidad Austral de Chile) for help in the field, and A. Iroumé and A. Huber (Universidad Austral de Chile) for logistic and technical assistance. We also thank two anonymous reviewers whose comments significantly improved an earlier version of this manuscript. This work was partially funded by the International Office of the BMBF (German Ministry for Education and Research) and Conicyt (Comisión Nacional de Investigación Científica y Tecnológica de Chile) and the "Potsdam Graduate School of Earth Surface Processes", funded by the State of Brandenburg.

Edited by: N. Romano

\section{References}

Bachmann, J., Ellies, A., and Hartge, K. H.: Development and application of a new sessile drop contact angle method to assess soil water repellency, J. Hydrol., 231, 66-75, 2000.

Bardossy, A. and Lehmann, W.: Spatial distribution of soil moisture in a small catchment. Part 1: Geostatistical analysis, J. Hydrol., 206, 1-15, 1998.

Blume, T., Zehe, E., and Bronstert, A.: Rainfall runoff response, event-based runoff coefficients and hydrograph separation, Hydrol. Sci. J., 52, 843-862, 2007.

Blume, T., Zehe, E., Reusser, D., Bauer, A., Iroumé, A., and Bronstert, A.: Investigation of runoff generation in a pristine, poorly gauged catchment in the Chilean Andes. I: A multi-method experimental study, Hydrol. Proc., 22, 3661-3675, 2008a.

Blume, T., Zehe, E., and Bronstert, A.: Investigation of runoff generation in a pristine, poorly gauged catchment in the Chilean Andes. II: Qualitative and quantitative use of tracers at three different spatial scales., Hydrol. Proc., 22, 3676-3688, 2008b.

Brocca, L., Morbidelli, R., Melone, F., and Moramarco, T.: Soil moisture spatial variability in experimental areas of central Italy, J. Hydrol., 333, 356-373, 2007.

de Rooij, G. H.: Modeling fingered flow of water in soils owing to wetting front instability: a review, J. Hydrol., 231, 277-294, 2000.

de Rooij, G. H. and deVries, P.: Solute leaching in a sandy soil with a water-repellent surface layer: A simulation, Geoderma, 70, 253-263, 1996.

Dekker, L. W. and Ritsema, C. J.: How Water Moves in a Water Repellent Sandy Soil .1. Potential and Actual Water Repellency, Water Resour. Res., 30, 2507-2517, 1994.
Dekker, L. W. and Ritsema, C. J.: Wetting patterns and moisture variability in water repellent Dutch soils, J. Hydrol., 231, 148164, 2000.

Eguchi, S. and Hasegawa, S.: Determination and characterization of preferential water in unsaturated subsoil of Andisol, Soil Sci. Soc. Am. J., 72, 320-330, 2008.

Ellies, A.: Untersuchungen über einige Aspekte des Wasserhaushaltes vulkanischer Aschenböden aus der gemäßigten Zone Südchiles, PhD thesis, Technical University of Hannover, Germany, Hannover, 1975.

Frisbee, M., Allan, C., Thomasson, M., and Mackereth, R.: Hillslope hydrology and wetland response of two small zero-order boreal catchments on the Precambrian Shield, Hydrol. Proc., 21, 2979-2997, 2007.

Germann, P. F. and Zimmermann, M.: Water balance approach to the in situ estimation of volume flux densities using slanted TDR wave guides, Soil Sci., 170, 3-12, 2005.

Hasegawa, S.: Evaluation of rainfall infiltration characteristics in a volcanic ash soil by time domain reflectometry method, Hydrol. Earth Syst. Sci., 1, 303-312, 1997, http://www.hydrol-earth-syst-sci.net/1/303/1997/.

Hino, M., Odaka, Y., Nadaoka, K., and Sato, A.: Effect of Initial Soil-Moisture Content on the Vertical Infiltration Process - a Guide to the Problem of Runoff-Ratio and Loss, J. Hydrol., 102, 267-284, 1988.

Iroumé, A.: Transporte de sedimentos en una cuenca de montana en la Cordillera de los Andes de la Novena Region de Chile, Bosque, 24, 125-135, 2003.

Kienzler, P. and Naef, F.: Subsurface storm flow formation at different hillslopes and implications fro the "old water paradox", Hydrol. Proc., 22, 104-116, 2007.

Martinez, C., Hancock, G. R., Kalma, J. D. and Wells, T.: Spatiotemporal distribution of near-surface and root zone soil moisture at the catchment scale, Hydrol. Process., 22, 2699-2714, 2008.

McNamara, J. P., Chandler, D., Seyfried, M., and Achet, S.: Soil moisture states, lateral flow, and streamflow generation in a semiarid, snowmelt-driven catchment, Hydrol. Proc., 19, 4023-4038, 2005.

Meyles, E., Williams, A., Ternan, L., and Dowd, J.: Runoff generation in relation to soil moisture patterns in a small Dartmoor catchment, Southwest England, Hydrol. Proc., 17, 251264, 2003.

Musiake, K., Oka, Y., and Koike, M.: Unsaturated Zone SoilMoisture Behavior under Temperate Humid Climatic Conditions - Tensiometric Observations and Numerical Simulations, J. Hydrol., 102, 179-200, 1988.

Nieber, J. L.: Modeling finger development and persistence in initially dry porous media, Geoderma, 70, 207-229, 1996.

Nyberg, L.: Spatial variability of soil water content in the covered catchment at Gardsjon, Sweden., Hydrol. Proc., 10, 89-103, 1996.

Poulenard, J., Michel, J. C., Bartoli, F., Portal, J. M., and Podwojewski, P.: Water repellency of volcanic ash soils from Ecuadorian paramo: effect of water content and characteristics of hydrophobic organic matter, Eur. J. Soil Sci., 55, 487-496, 2004.

Rezzoug, A., Schumann, A., Chifflard, P., and Zepp, H.: Field measurement of soil moisture dynamics and numerical simulation using the kinematic wave approximation, Adv. Water Resour., 28, 917-926, 2005. 
Ritsema, C. J. and Dekker, L. W.: How Water Moves in a Water Repellent Sandy Soil .2. Dynamics of Fingered Flow, Water Resour. Res., 30, 2519-2531, 1994.

Ritsema, C. J. and Dekker, L. W.: Distribution Flow - a General Process in the Top Layer of Water Repellent Soils, Water Resour. Res., 31, 1187-1200, 1995.

Ritsema, C. J. and Dekker, L. W.: Water repellency and its role in forming preferred flow paths in soils, Aust. J. Soil Res., 34, 475-487, 1996.

Ritsema, C. J. and Dekker, L. W.: Preferential flow in water repellent sandy soils: principles and modeling implications, J. Hydrol., 231, 308-319, 2000.

Ritsema, C. J., Dekker, L. W., Nieber, J. L., and Steenhuis, T. S.: Modeling and field evidence of finger formation and finger recurrence in a water repellent sandy soil, Water Resour. Res., 34, 555-567, 1998.

Robinson, D. A., Campbell, C. S., Hopmans, J. W., Hornbuckle, B. K., Jones, S. B., Knight,R., Ogden, F., Selker, J., Wendroth, O.: Soil moisture measurement for ecological and hydrological watershed-scale observatories: A review, Vadose Zone J., 7, 358-389, 2008.

Selker, J. S., Steenhuis, T. S., and Parlange, J. Y.: An engineering approach to fingered vadose pollutant transport, Geoderma, 70, 197-206, 1996.

Shoji, S., Nanzyo, M., and Dahlgren, R.: Volcanic ash soils - genesis, properties and utilization, in: Developments in soil science, vol. 21, 189-207, Elsevier, Amsterdam, The Netherlands, 1993.

Starr, J. L. and Timlin, D. J.: Using high-resolution soil moisture data to assess soil water dynamics in the vadose zone, Vadose Zone J., 3, 926-935, 2004.
Taumer, K., Stoffregen, H., and Wessolek, G.: Seasonal dynamics of preferential flow in a water repellent soil, Vadose Zone J., 5, 405-411, 2006.

Van't Woudt, B.: On factors governing subsurface storm flow in volcanic ash soils, New Zealand, Eos T. Am. Geophys. Un., 35, 136-144, 1954.

Vereecken, H., Huisman, J. A., Bogena, H., Vanderborght, J., Vrugt, J. A. and Hopmans, J. W.: On the value of soil moisture measurements on vadose zone hydrology: A review, Water Resour. Res., 44, W00D06, doi:10.1029/2008WR006829, 2008.

Weiler, M. and Naef, F.: An experimental tracer study of the role of macropores in infiltration in grassland soils, Hydrol. Proc., 17, 477-493, 2003.

Western, A. W., Zhou, S.-L., Grayson, R. B., McMahon, S. D., Bloschl, G., and Wilson, D. J.: Spatial correlation of soil moisture in small catchments and its relationship to dominant spatial hydrological processes, J. Hydrol., 286, 113-134, 2004.

Williams, A. G., Dowd, J. F., Scholefield, D., Holden, N. M., and Deeks, L. K.: Preferential flow variability in a well-structured soil, Soil Sci. Soc. Am. J., 67, 1272-1281, 2003.

Zhou, Q. Y., Shimada, J., and Sato, A.: Three-dimensional spatial and temporal monitoring of soil water content using electrical resistivity tomography, Water Resour. Res., 37, 273-285, 2001.

Zhou, Q. Y., Shimada, J., and Sato, A.: Temporal variations of the three-dimensional rainfall infiltration process in heterogeneous soil, Water Resour. Res., 38, 1030, doi:10.1029/2001WR000349, 2002. 